\title{
تقييم الأداء الوظيفي لملابس عمال النظافة بمحافظة الدقهلية"
}

\author{
إعلداد \\ د/ نورا حسر إبراهيم العدوكي \\ د أبنب أحمد عبدالعزيز \\ أستاذ النسيج والملابس المساعد \\ أستاذ الملابس والنسيج المساعد \\ كلية التربية النوعية - جامعة المنصورة \\ كلية التربية النوعية - جامعة المنصورة \\ أ. إيمابـ فوده محمد الغندور صيام \\ باحث ماجستير
}

مجلة بحوث التربية النوعية ـ جامعة المنصورة

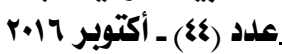

بحث مستل من رسالة ماجستير 


\title{
تقييم الأداء الوظيفي لهلابس عمال النظافة بمحافظة الدقهاية
}

\author{
إعداد \\ د/نوراحسنإبراهيم العدوي

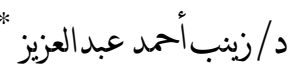 \\ أ أ. إيمازفودهممد الغندور صيام
}

استهدف البحث التعرف على مستوى جودة الأداء الوظيفي لملابس عمال النظافة بمحافظة

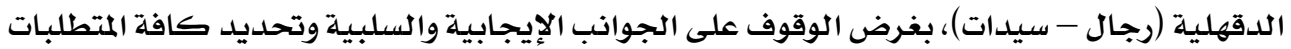

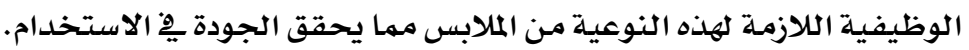

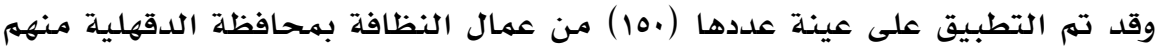

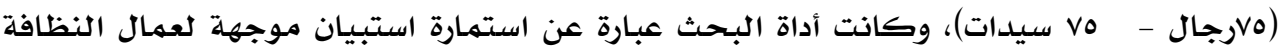

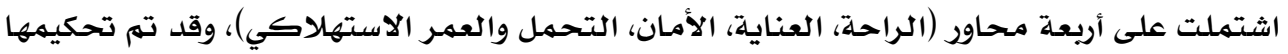

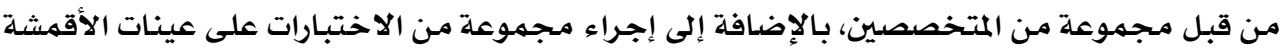

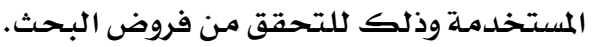

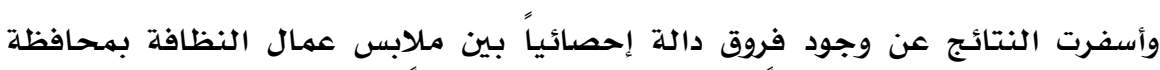

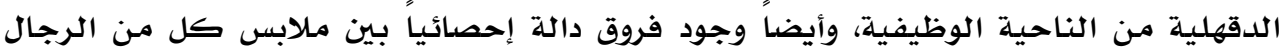

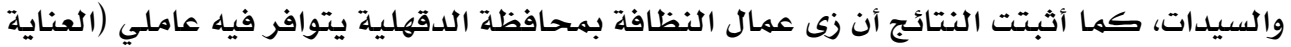

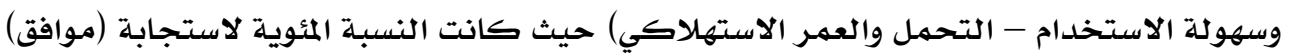

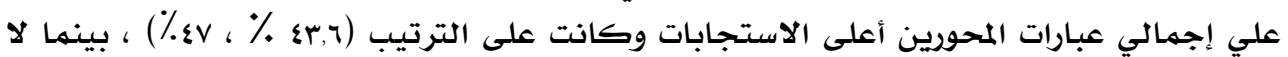

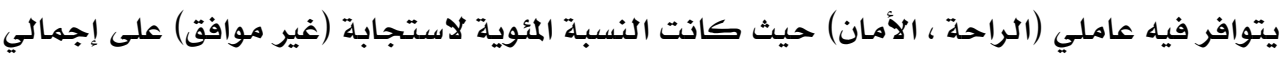

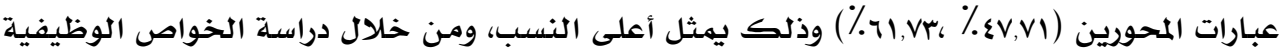

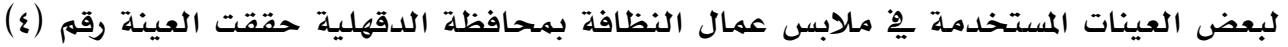

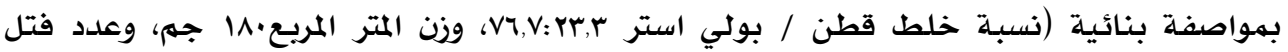

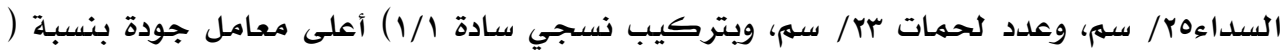




\section{ت بقييم الأداء الوظيفي لملاوبس بعض عمال النظافة بمحافظة الدقهلية \\ هقدهمة البحث:}

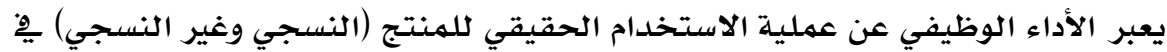

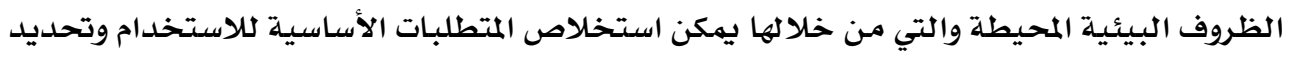

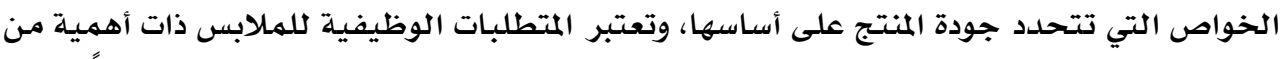

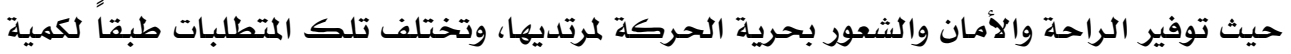

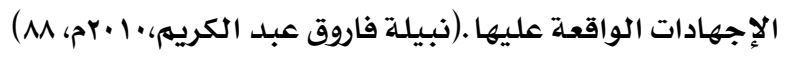

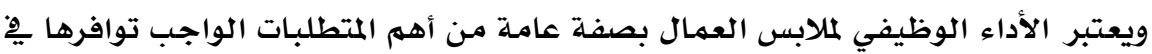

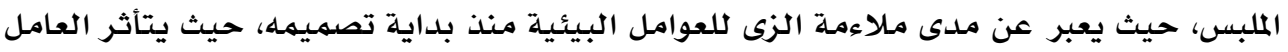

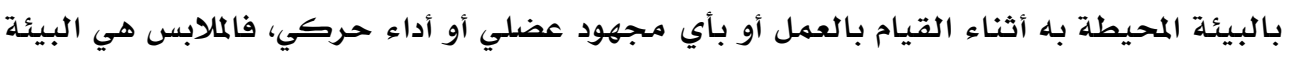

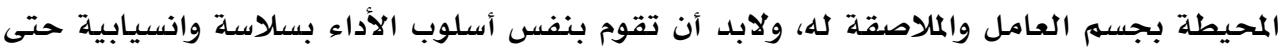

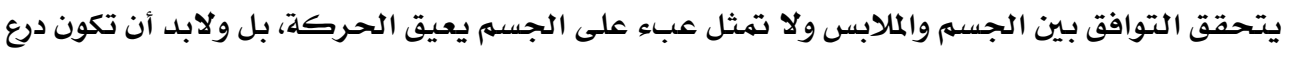

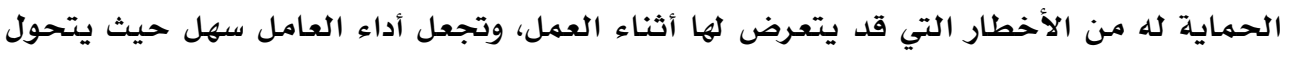

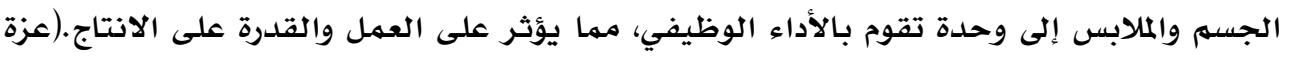

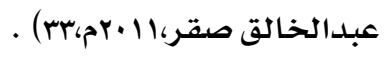
ويختلف الأداء الوظيفي لملابس عمال النظافة باختلاف نوع العهل الذي يمارسـه هؤلاء

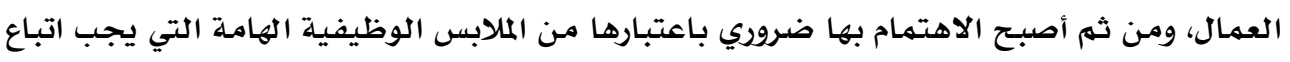
الأسلوب العلمي الصحيح عند الختيارها.

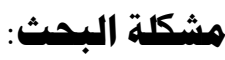

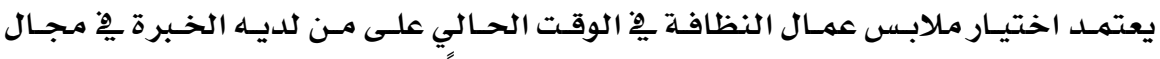

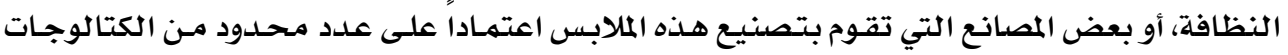

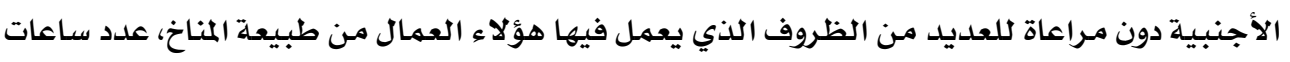

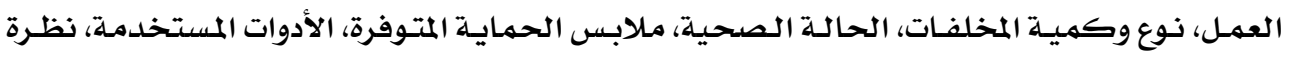
المجتهمع لهذه المهنة.

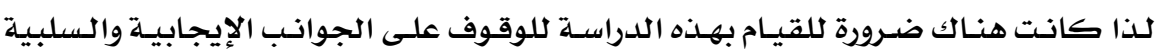

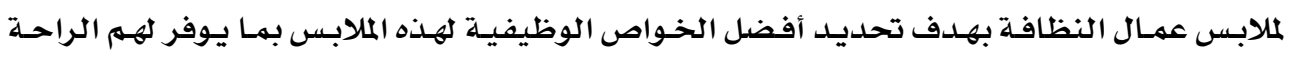

الجسمية والنفسية.

وتتلخص مشكلة البحث يِ التساؤل الرئيسي التالي:

• ما جودة الأداء الوظيفي لمابلابس بعض عمال النظافة بمحافظة الدقهلية؟ ويتفرع من هذا التساؤل الرئيسي عدة تساؤلات فرعية هي:

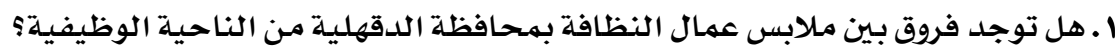

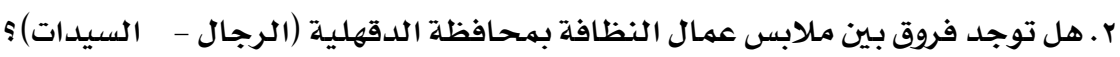




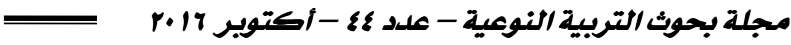

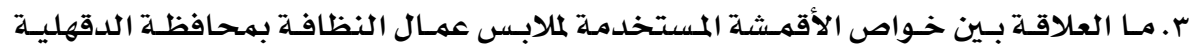

$$
\text { أهـية البحث: وكفاءة الأداء الوظيفي؟ }
$$

ا ـ الوقوف على المتطلبات الوظيفية لزي عمال النظافة والتي تساعد ٍِِ إضفاء الراحة الجسمية

$$
\text { والنفسية لهم. }
$$

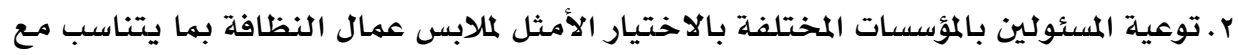

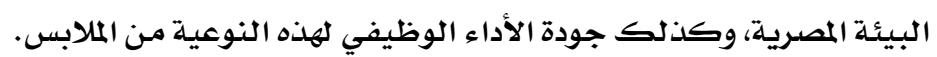

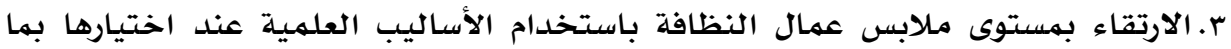

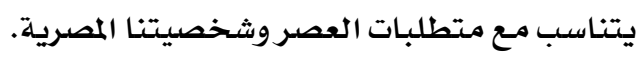

\section{أهداف البحث:}

$$
\text { يهدف البحث إلى ما يلي: }
$$

I. التعرف على الفروق بين ملابس عمال النظافة بهحافظة الدقهلية من الناحية الوظيفية.

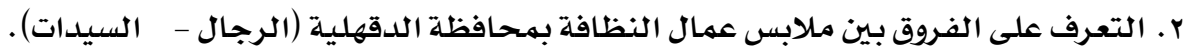

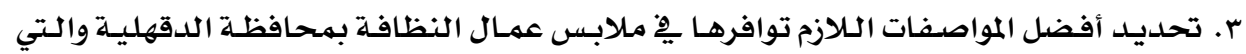

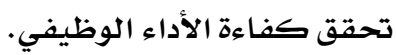

ا.توجد فروق ذات دلالة إحصائية بين ملابس عمال النظافة بمحافظة الدقهلية من الناحية

$$
\text { الوظيفية. }
$$

r. لا توجد فروق ذات دلالة إحصائية بين ملابس عمال النظافة بمحافظة الدقهلية (الرجال -

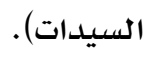

r. توجد علاقة دالة إحصائياً بين خواص الأقمشة المستخدمـة لملابس عمال النظافة بهحافظة

$$
\begin{aligned}
& \text { الدقهلية وجودة الأداء الوظيفي. } \\
& \text { هنهه البحث: } \\
& \text { تم استخدام كلاً من: } \\
& \text { • المنهج الوصفي التحليلي. } \\
& \text { • المنهج التجريبي. } \\
& \text { أدوات البحث: }
\end{aligned}
$$

ا.استمارة استبيان موجهة لعمال النظافة بمحافظة الدقهلية بهدف تقييم الجانب الوظيفي

$$
\text { ملابس عملهم. }
$$


r.الأدوات والأجهزة المستخدمة لتحديد خواص أقمشة ملابس عمال النظافة عينة الدراسة وهى كالتالي:

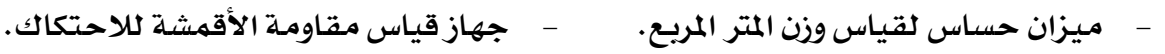

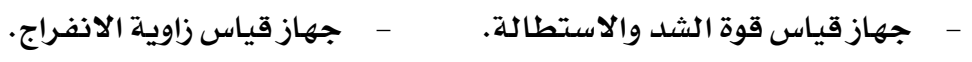

ا. حدود مكانية: بعض الأماكن التي يستخلدم فيها زي خاص (يونيفورم) لعمال النظافة مثل:

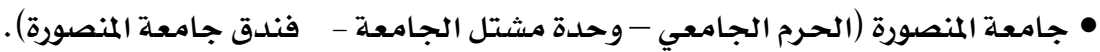

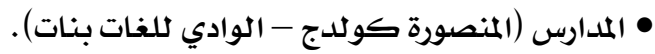

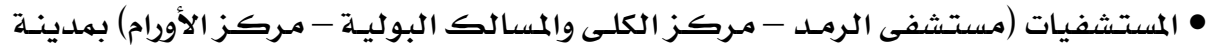
المنصورة. (.حدود بشرية: عمال النظافة الذين يستخدمون زياً خاصاً (يونيفورم) أثناء القيام بعملهم،

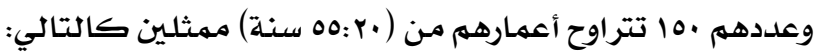

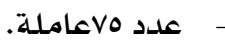

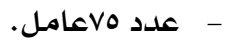
همطات البمث:

\section{ا ـ الأداء الوظيفي: Functional Performance}

هو عملية الاستخدام الحقيقي للمنتج (النسجي أو غير النسجي) فِّ الظروف البيئية

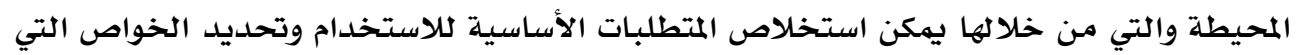

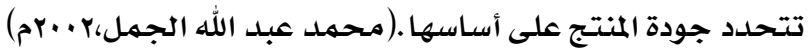

Y. الملابس الوظيفية: Functional clothing

هي الملابس التي يرتديها مجموعة من الأفراد الذين يؤدون أعما لهم داخل المنشآت المختلفة، الماتهاء

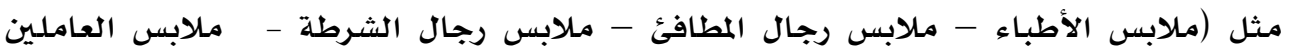

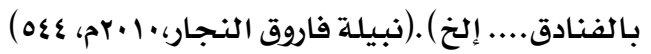

\section{r. ملابس العمال: Clothing workers}

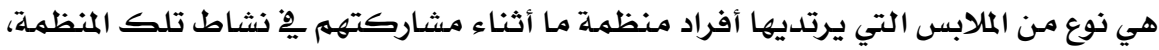

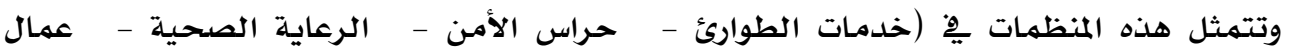
النظافة..). (Pratt, 1993,33) \&. مالابس عمال النظافة (إجرائياً):

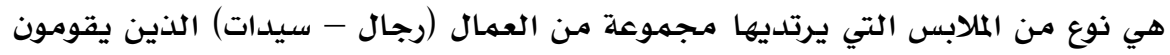

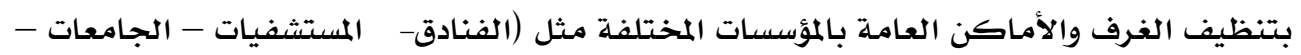




\section{الجانب النظري لابمث البمان}

أولاً: ملابس عمال النظافة:

تتأثر ملابس عمال النظافة تأثراً ملحوظاً بالظروف المحيطة وطبيعة العمل والاحتكاك

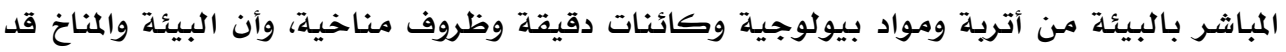

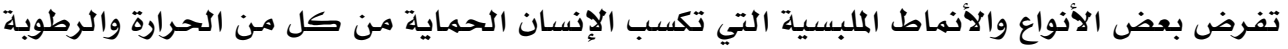

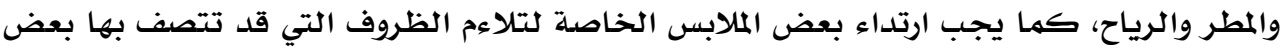

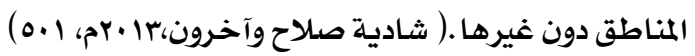

وقد اهتمت العديد من الدراسات بملابس عمال النظافة، فتذكر (سها محمد عبدالدالرازق،

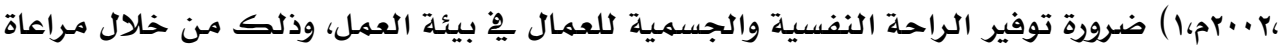

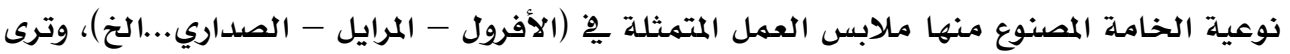

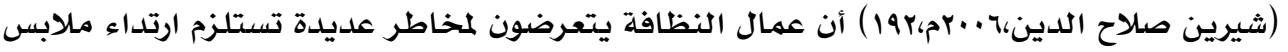

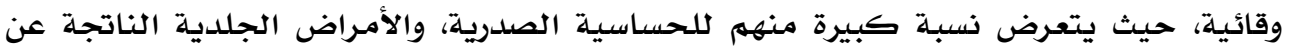

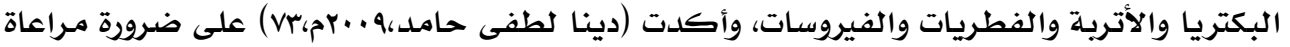

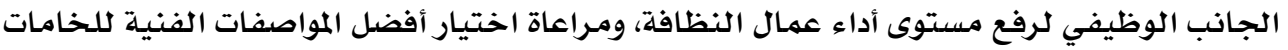

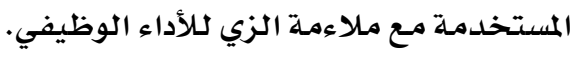

وقد ذكرت (رحاب مبروك عبدالله،ه +.بم،1|) ضرورة وضع معايير فنية لملابس العمال بحيث تتفق هذه المعايير مـع خصائص بيئة العمل، حيث يعمل ذلك الك على تحقيق جودة الأداء

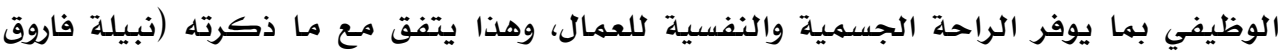

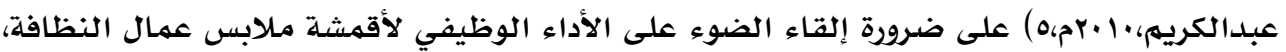

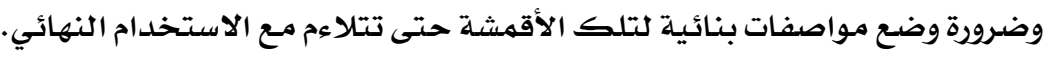

\section{ثانياً: التطلبات الوظيفية لملابس عمال النظافة:}

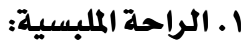

تعد الراحة من الخواص الهامـة الواجب توافرها ِِِ أقمشة ملابس العمال، وتختلف

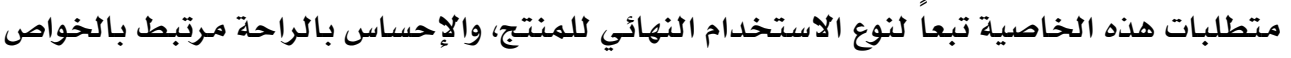

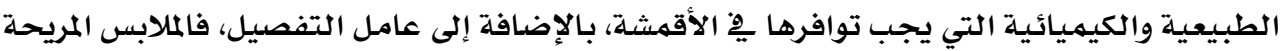

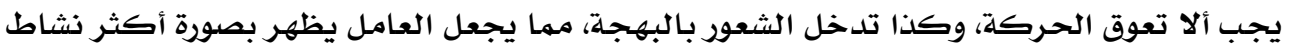

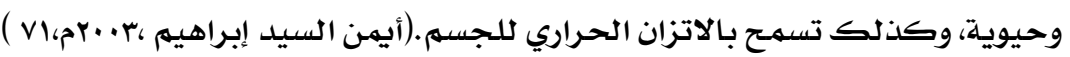

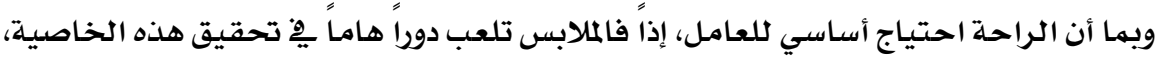

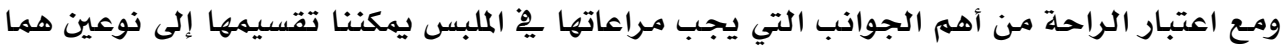

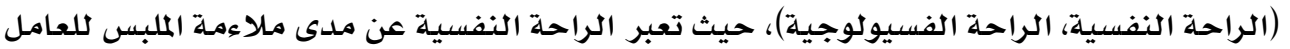

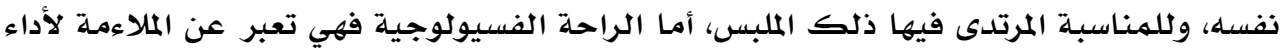

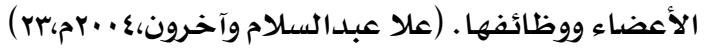




\section{ب تقييم الأداء الوظيفي بلابس بعض عمال النظافة بمحافظة الدقهلية

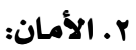

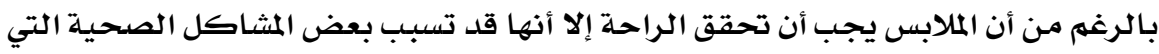

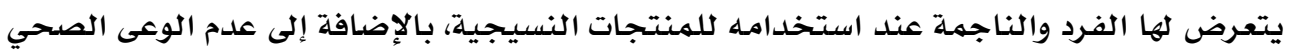

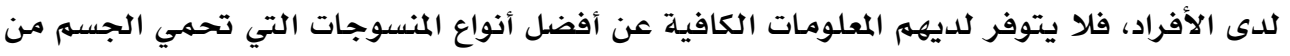

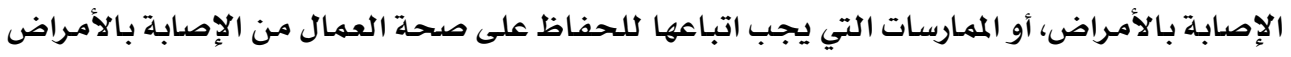

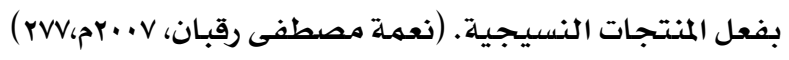

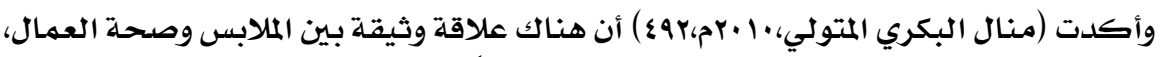

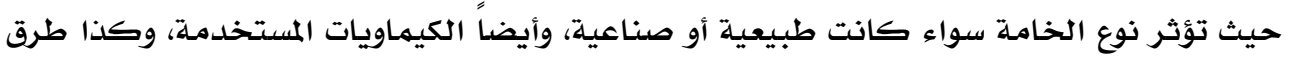

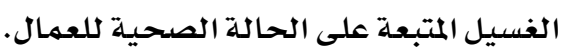

ويتمثل الأمان لملابس العمال يِّ عدة عوامل منها (الحماية من المواد الكيماويـة، مقاومـة

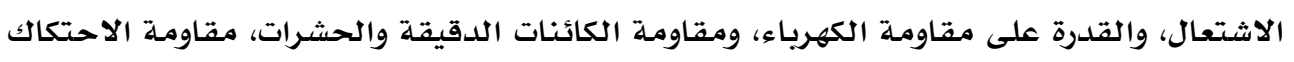

بالجلد). (http//:www.vitliligoarab.net)

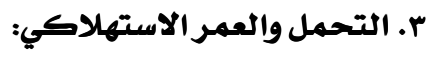

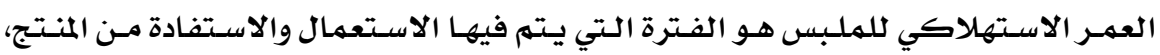

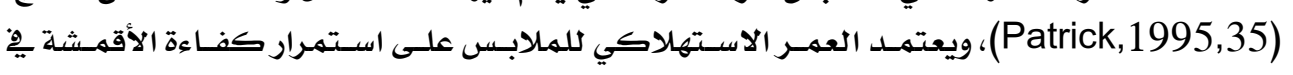

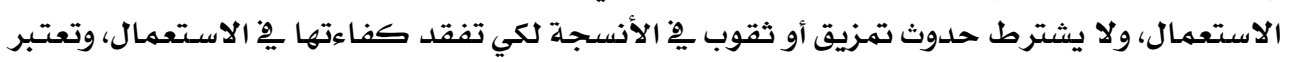

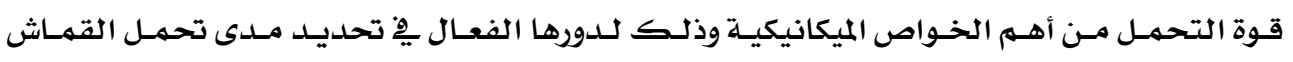

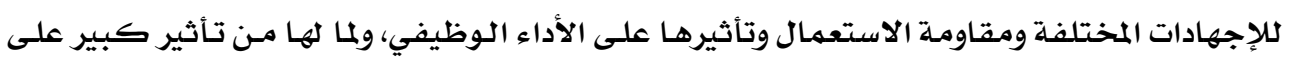

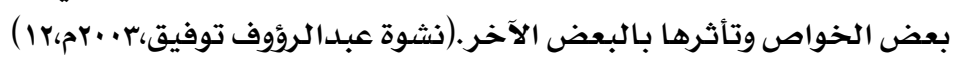

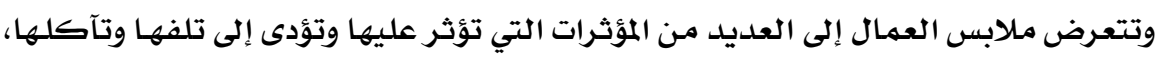

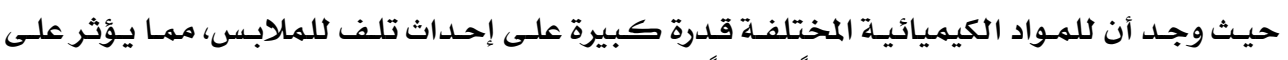

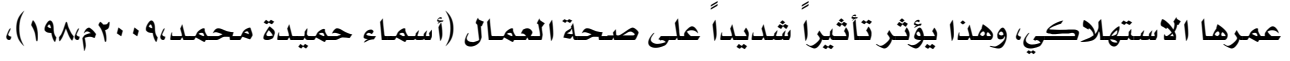

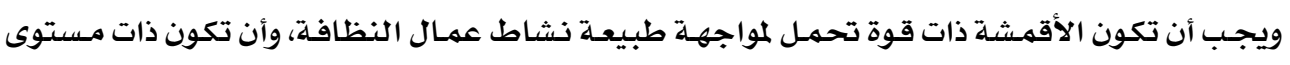

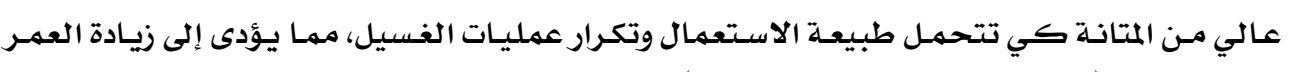

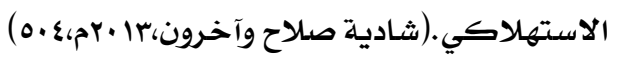

ع. سهولة الاستخدام (العناية):

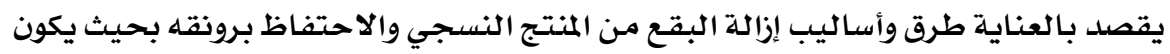

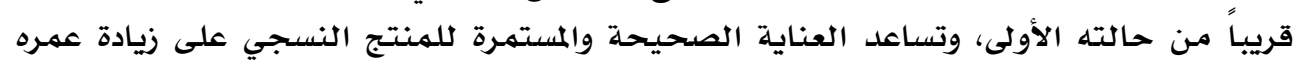

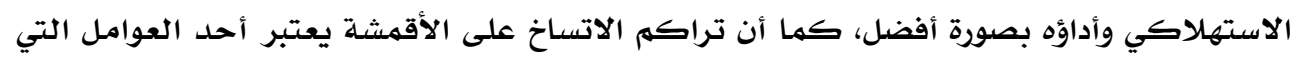

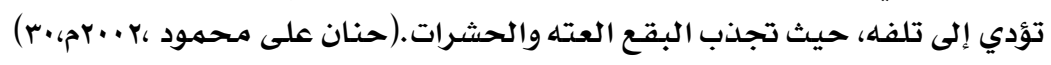
ومن الاعتبارات الهامـة التي يجب أن تتميز بها أقمشة ملابس العمال لتحقيق سهولة

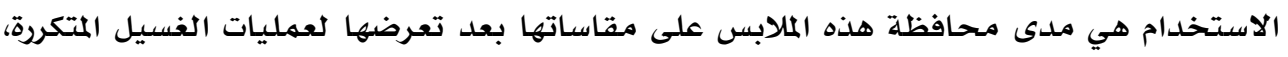


بالإضافة إلى مقاومتها للانكماش، واحتفاظها بشكلها أثناء الاستخدام، ومقاومـة الاتساخ وثبات ألوانها.(Kathry, 1992,32)

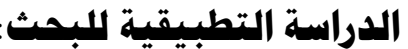

انقسمت الدراسة التطبيقية للبحث إلى جانبان:

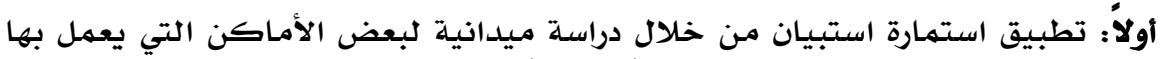

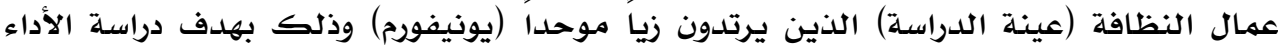

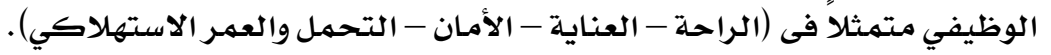

ثانياً: إجراء بعض الاختبارات على عينات مـن أقمشة ملابس عمال النظافة (عينة الدراسـة)

وذلك بهدف تقييه الأداء الوظيفي، والوقوف على الجوانب الإيجابية والسلبيـة لتلك الأقمشة.

أولاً: تطبيق استمارة الاستبييان:

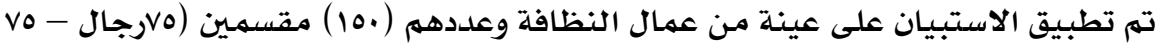

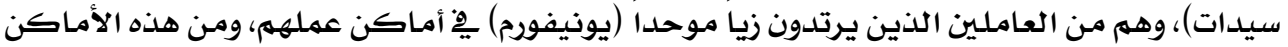
والتي تم التطبيق بها:

$$
\text { • • جامعة المنصورة (الحرم الجامعي - وححدة مشتل الجامعة - فندق جامعة المنصورة). }
$$

• المستشفيات (مستشفى الرمد - مركز الكلى والمسالك البولية - مركز الأورام) بمدينة

$$
\text { المنصورة. }
$$

قياس صلدق وثبات استمارة الاستبيان:

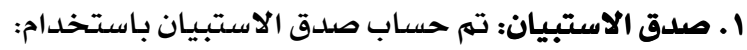

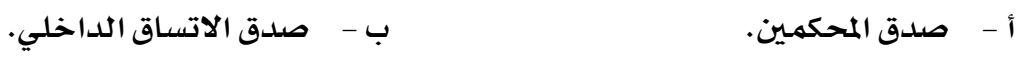

$$
\text { أ - أ - مدق المحكمين: }
$$

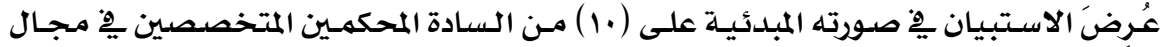

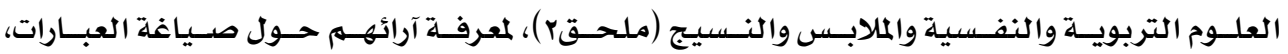

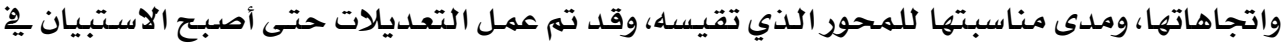

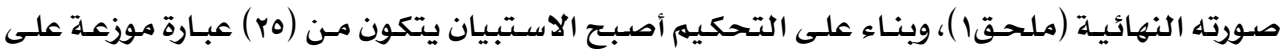
أربعة محاور أساسية كالتالي:

$$
\begin{aligned}
& \text { ا ـ محور الراحة (v) عبارات. } \\
& \text { r. r. محور العناية (ه) عبارات. } \\
& \text { r. محور الأمان (ه) عبارات. محور العيات. }
\end{aligned}
$$

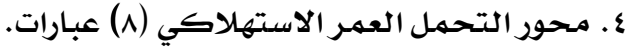


وتحددت استجابات عينة البحث على كل عبارة وفق ثلاث استجابات (موافق - موافق إلى موافى

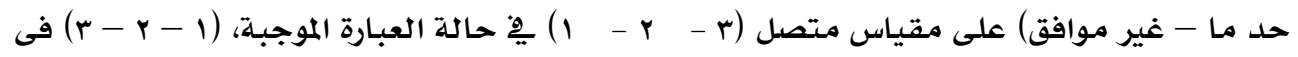

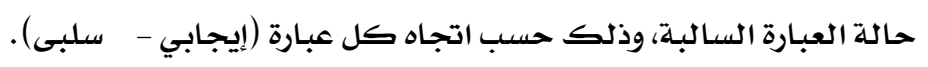

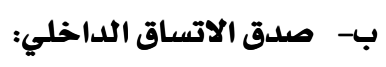

تم حساب الصدق باستخدام الاتساق الداخلي وذلك بحساب معامل الارتباط (معامل

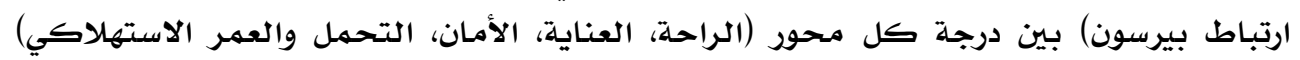

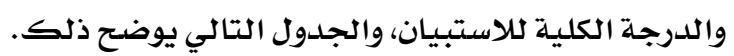

جدول رقم (1) قيم معاملات الارتباط بين درجة كل محور والدرجة الكلية للاستبيان

\begin{tabular}{|c|c|c|}
\hline مستوى الدلالة & قيمـة معامل الارتباط & المحاور \\
\hline دالة عند ا+,. & *,१९q & الراحة \\
\hline دالة عند ه.,. & *,rтq & العناية \\
\hline دالة عند ا+,. & $* *, \wedge \wedge \vee$ & الأمسان \\
\hline دالة عند ا+,. & $* *, \mathrm{vaV}$ & التحمل والعمـر الاستهلاكي \\
\hline
\end{tabular}

يتضح من الجدول رقم (1) أن قيم معامـلات الارتباط بين درجة كل محور والدرجة الكلية

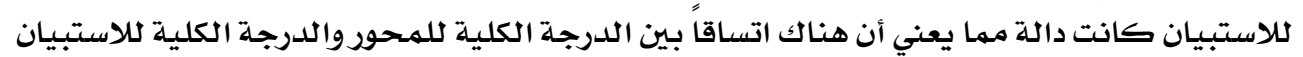

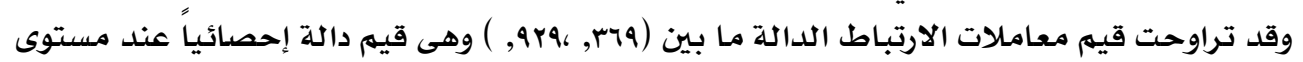

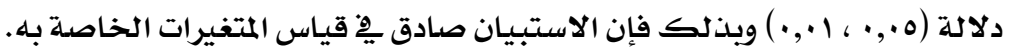

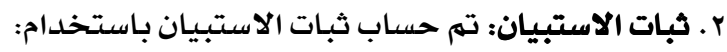

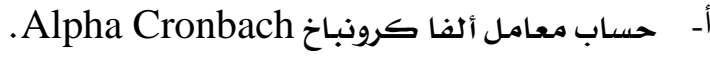

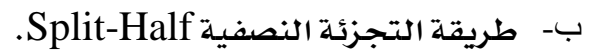
جدول رقم (ץ) قيم ثبات الاستبيان لكل من معامل ألفا والتجزئة النصفية

\begin{tabular}{|c|c|c|c|}
\hline \multicolumn{2}{|c|}{ التجزئـة النصفية } & \multirow{2}{*}{ معامل ألفا } & \multirow{2}{*}{ المحاور } \\
\hline جتمان & سبيريرمان & & \\
\hline,$\wedge Y \wedge$ & , ^০r &, $1 \cdot 9$ & الراحة \\
\hline , V70 &, $\mathrm{VVr}$ &,$v \leqslant 1$ & العناية \\
\hline,$\wedge \vee \cdot$ &,$\wedge \vee q$ &, $\mathrm{v} 79$ & الأمان \\
\hline$\cdot, \Lambda \cdot \varepsilon$ & $\cdot, \wedge \cdot 0$ & , TrA & التحمل \\
\hline - ,qrV & - , qrV & $\cdot, \wedge \top \wedge$ & الأداء الوظيفي ككل \\
\hline
\end{tabular}

يتضح من الجدول رقم (Y) أن معامل ألفا للمحاور كانت دالة، كذلك كان مان معامل ألفا

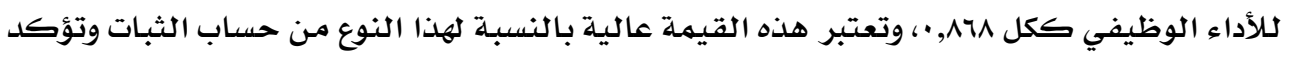




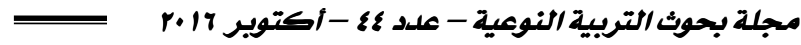

ثبات الاستبيان، وأن معامل ارتباط التجزئة النصفية للمحاور كانت دالة للاستبيان ككل بقيمة هYV ثانياً: اختبارات الأقمشة:

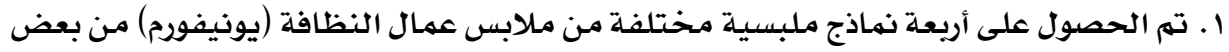

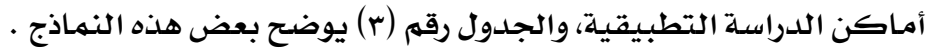

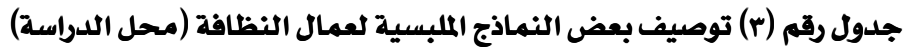

\begin{tabular}{|c|c|c|c|}
\hline التوصيف & مكان الحصول عليه & النموذج & $\hat{A}$ \\
\hline 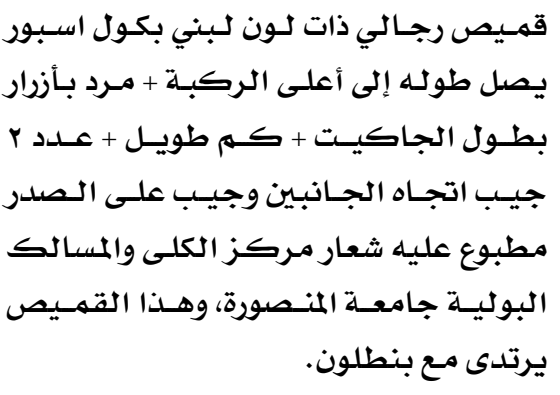 & مركز المسالكسلى البولية & & 1 \\
\hline 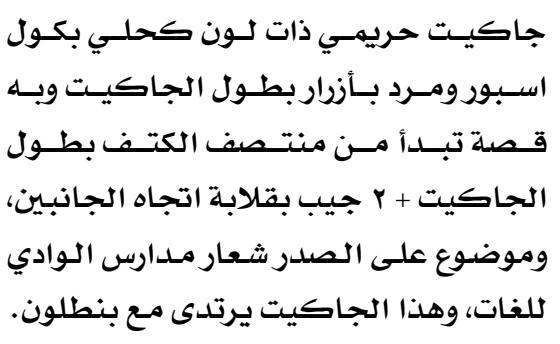 & مدارس الوادي & & $r$ \\
\hline
\end{tabular}

r. تم تجهيز (ع ) عينات بهمدل عينة من كل نهوذج مـن النهـاذج التي تم الحصول عليها لإجـراء

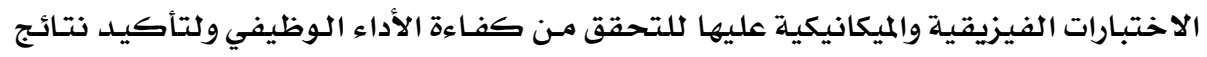

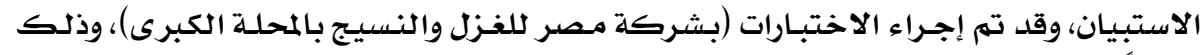

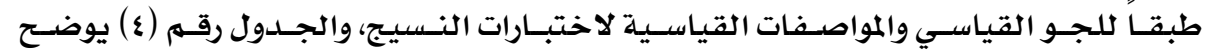

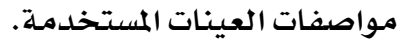


جدول رقم (§) مواصفات الأقمشة عينة الدراسة

\begin{tabular}{|c|c|c|c|c|c|}
\hline عينةع & عينها & عينهr & عينة| & المواصفات & م \\
\hline$V 7, V: r r, r$ & $v 0,1: r \leqslant, 9$ & $1 \cdots: \cdot$ & $V 0, \varepsilon: Y \leqslant, T$ & نسبة الخلط قطن / بولي استر & 1 \\
\hline سادة 1/1 & سـادة 1/1 & سادة 1/1 & سادة 1/1 & التركيب النسجي & r \\
\hline ro & T & ro & ro & عدد فتل السداء / سهم & $r$ \\
\hline r & r & rl & ro & عدد اللحمـات / سهم & $\varepsilon$ \\
\hline $1 \wedge$. & ryo & $1 \wedge 7$ & $10 \xi$ & وزن المتر المريـع (جهم) & 0 \\
\hline
\end{tabular}

النتائج وهناقشتها:

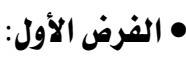

توجد فروق ذات دلالة إحصائية بين ملابس عمال النظافة بمحافظة الدقهلية من الناحية

الوظيفية.

للتحقق من صحة هذا الفرض تم تطبيق الاستبانة على عينة البحث من عمال النظافة،

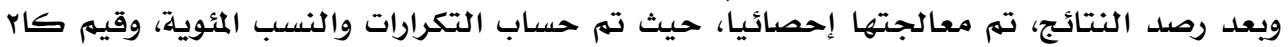

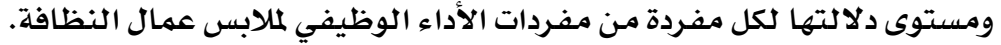
أولاً: المحور الأول (الراحة):

جدول رقم (ه) التكرارات والنسب المئوية وقيم كاب ومستوي الدلالة

لاستجابات عمال النظافة علي المحور الأول الخاص بالراحة ن = 10 10

\begin{tabular}{|c|c|c|c|c|c|c|c|c|c|}
\hline \multirow{3}{*}{ مستوى الدلالة } & \multirow{3}{*}{ Sו } & \multicolumn{6}{|c|}{ فئات الاستجابة } & \multirow{3}{*}{ 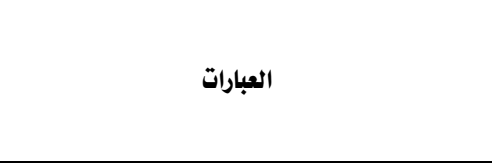 } & \multirow{3}{*}{ ค } \\
\hline & & \multicolumn{2}{|c|}{ غير موافق } & \multicolumn{2}{|c|}{ إلى حلد ما } & \multicolumn{2}{|c|}{ 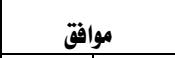 } & & \\
\hline & & |النسبة\%٪ & التكرار & |النسبة:\% & التكرار & |النسبة\%٪ & التكرار & & \\
\hline,+1 & $I I I, \vee$ & V乏 & 111 & ir & 11 & Is & $r^{\prime}$ & |يتناسب الزى مع فصلي الصيف والشتاء & 1 \\
\hline,+1 & rq, Ir & $\Delta \varepsilon$ & $\wedge 1$ & $1 \varepsilon$ & ri & rr & $\xi \wedge$ & |المقاسات المتوفرة من الزى تلبي احتياجاتي. & $r$ \\
\hline,+1 & $77, \mathrm{Vr}$ & $7 \varepsilon$ & 97 & ir & 11 & rz & m & أشعر بالراحة عندما ارتدي الزى أثناء العمل. & $r$ \\
\hline,$\cdot 1$ & $\mathbb{1 \Lambda , \Lambda \varepsilon}$ & rq & rq & rs & rq & 0. & vo & |توجد صعوبة عند ارتداء وخلع الزى. & $\varepsilon$ \\
\hline,+1 & $01, Y \xi$ & 7. & q. & $1 \varepsilon$ & ri & rq & rq & |خامة الزى مريحة وتقتص العرق. & 0 \\
\hline, .1 & $111, \vee$ & $1 \varepsilon$ & rI & ir & 11 & v\& & 111 & ليعمل الزي خلال فترة العمل على رفع درجة حرارة جسمي. & 7 \\
\hline, .0 & v,rr & $\xi r$ & Tr & rร & rq & rళ & 01 & | يمتاز الزى بنعومة الملمس. & $\checkmark$ \\
\hline
\end{tabular}

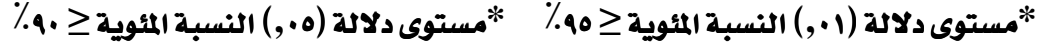


يتضح من الجدول رقم (0) وجود فروق دالة إحصائياً عند مستوى (1., (.) بين استجابات

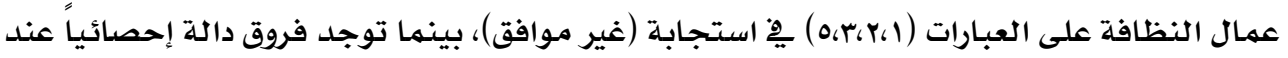

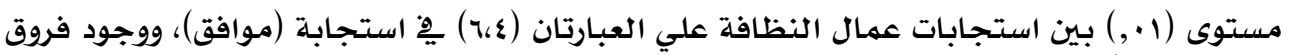

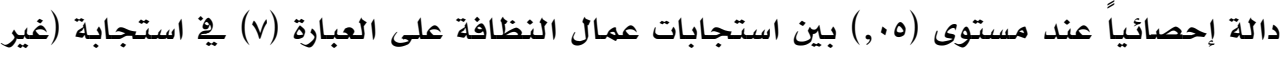
موافق).

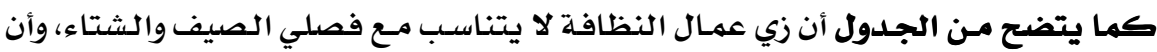

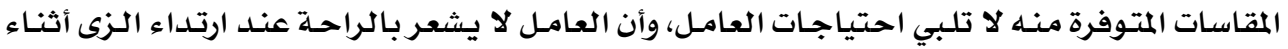

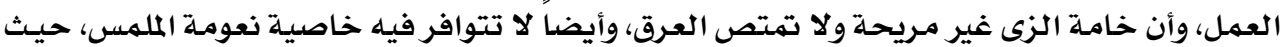

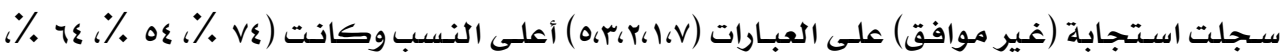

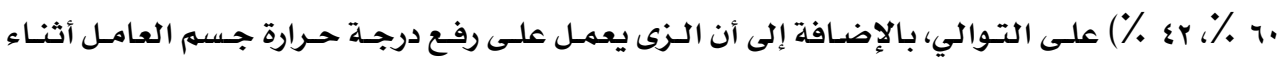

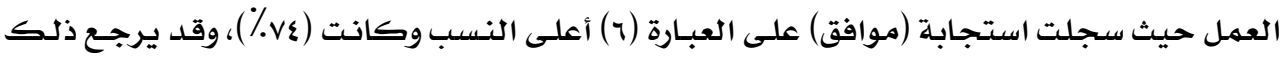

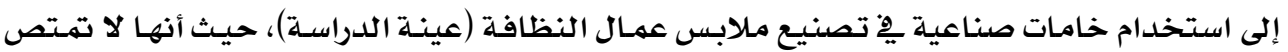

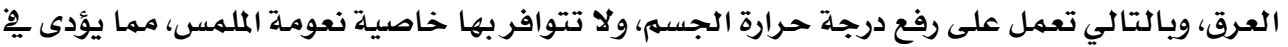

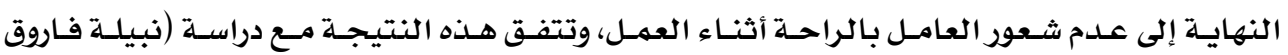

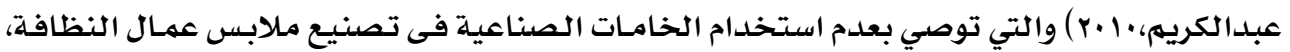

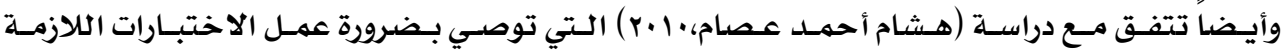

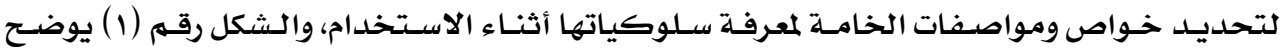

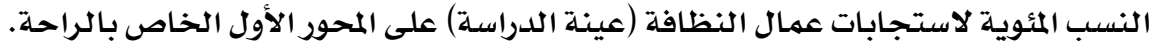

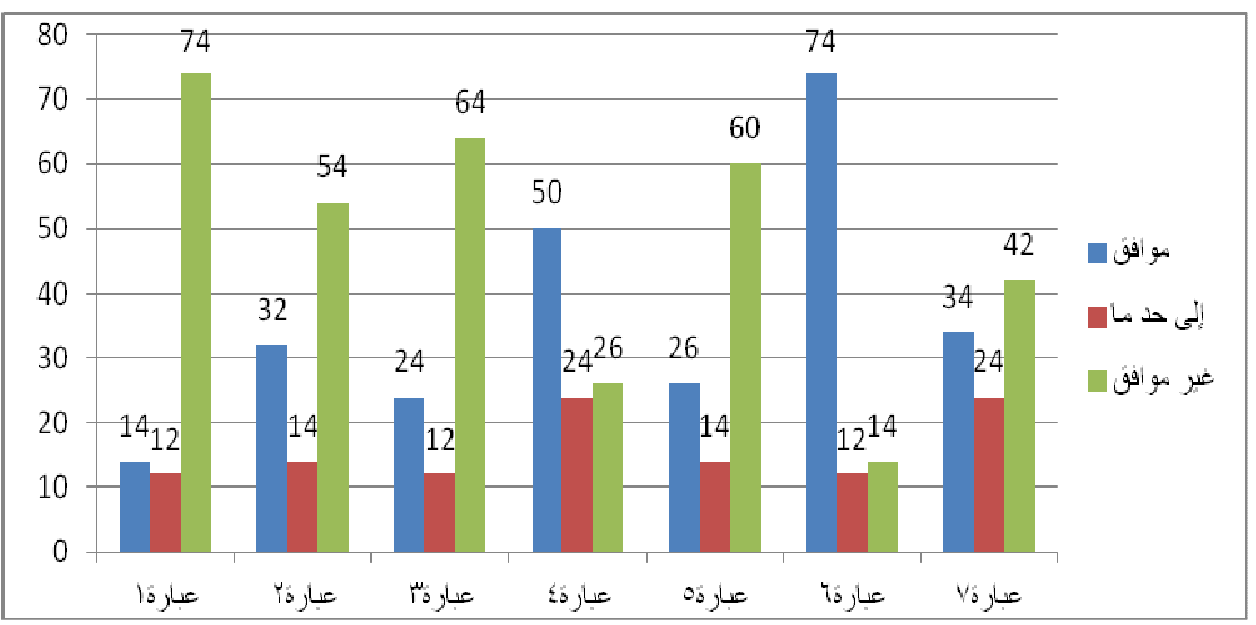

الشكل رقم (1) النسب المئوية لاستجابات عمال النظافة على المحور الأول (الراحة) 


\section{= = تقييم الأداء الوظيفي لملابس بعض عمال النظافة بمحافظة الدقهلية \\ ثانياً: المحور الثاني ( العناية ) :}

جدول رقم (7) التكرارات والنسب المئوية وقيم كاب ومستوى

الدلالة لاستجابات عمال النظافة على المحور الثاني الخاص بالعناية ن= .10

\begin{tabular}{|c|c|c|c|c|c|c|c|c|c|}
\hline \multirow{3}{*}{ مستوى الدلالة } & \multirow{3}{*}{ ris } & \multicolumn{6}{|c|}{ 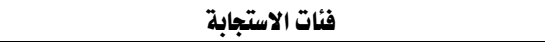 } & \multirow{3}{*}{ 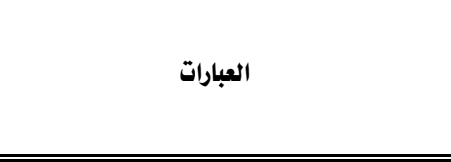 } & \multirow{3}{*}{ P } \\
\hline & & \multicolumn{2}{|c|}{ غير موافق } & \multicolumn{2}{|c|}{ إلى حد ما } & \multicolumn{2}{|c|}{ موافق } & & \\
\hline & & | النسبة.٪ & 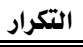 & |النسبة \% & التكرار & النسبة \% & التكرار & & \\
\hline,$\cdot 1$ & $r q, 0$. & or & YA & 17 & rq & rr & $\xi \Lambda$ & | يتعرض الزى للاتساخ بسرعة. & 1 \\
\hline,+1 & $0 ., 0 \mathrm{r}$ & $\xi \wedge$ & rr & 9 & 9 & ६ฯ & 79 & |تزال البقع من الزى بسهولة أثناء الفسيل & $r$ \\
\hline,+1 & $\forall r, \wedge \varepsilon$ & 79 & 99 & $1 \varepsilon$ & ri & r. & re & ينكمش الزى (تفير في الطول والعرض) بعد الفسيل. & $r$ \\
\hline,+1 & va,rr & rq & rq & $\wedge$ & ir & 77 & 99 & ليحتاج الزي للفسيل أكثر من مرة خلال الأسبوع. & $\varepsilon$ \\
\hline,+1 & rq, १६ & r. & r. & r & rq & $\Delta \xi$ & $\wedge 1$ & ليحتاج الزى للكي بعد عملية الغسيل. & 0 \\
\hline
\end{tabular}

يتضح من الجدول رقم (ج) وجود فروق دالة إحصائياً عند مستوى (1., ) بين استجابات

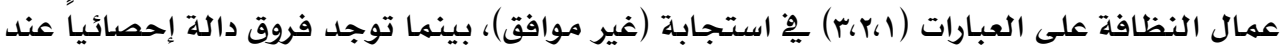

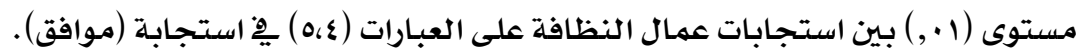
كما يتضح من الجدول أن زى عمال النظافة يتحمل الإتساخات أثناء فترة العمل، ويمتاز

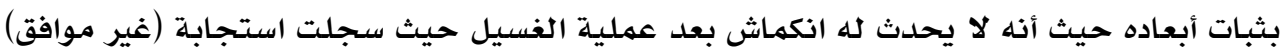

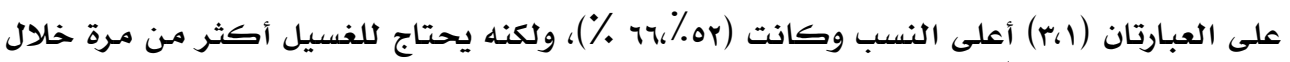

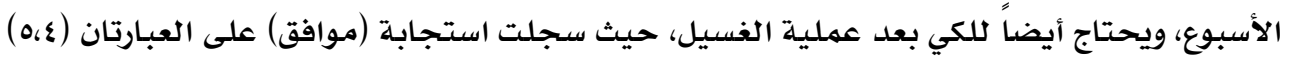

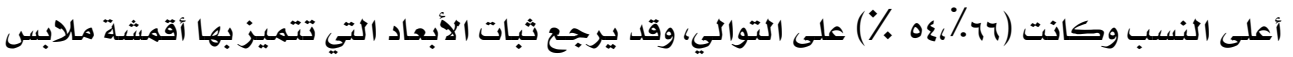

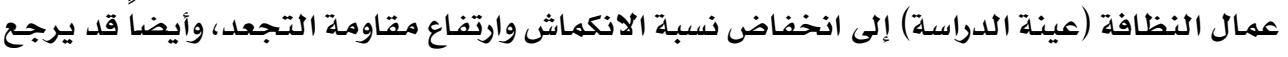

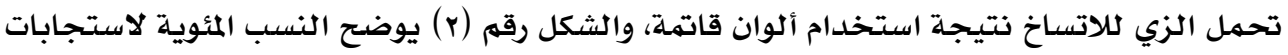

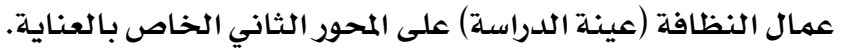

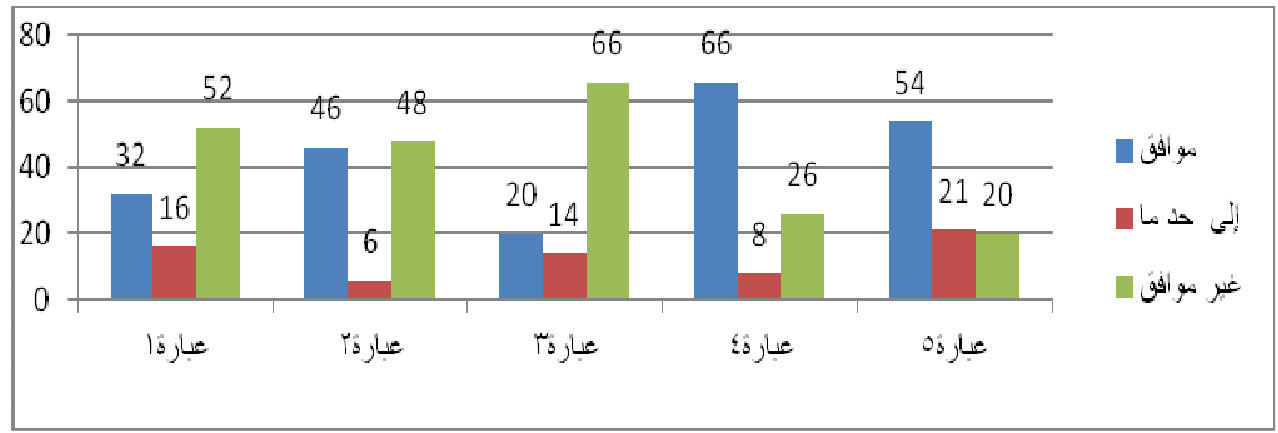

الشكل رقم (Y) النسب المئوية لاستجابات عمال النظافة على المحور الثاني (العناية) 
ثالثاً: المحور الثالث (الأمان):

جدول رقم (v) التكرارات والنسب المئوية وقيم كاب ومستوى الدلالة

لاستجابات عمال النظافة على المحور الثالث الخاص بالأمان ن= .10

\begin{tabular}{|c|c|c|c|c|c|c|c|c|c|}
\hline \multirow{3}{*}{ |الدلالة } & \multirow{3}{*}{ كוr } & \multicolumn{6}{|c|}{ 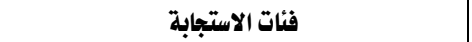 } & \multirow{3}{*}{ 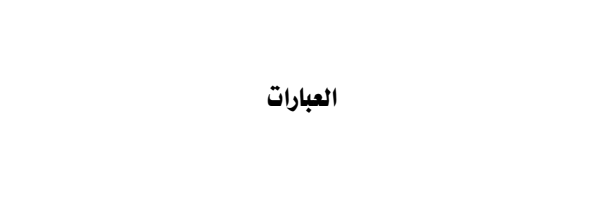 } & \multirow[b]{3}{*}{ 个 } \\
\hline & & \multicolumn{2}{|c|}{ غير موافق } & \multicolumn{2}{|c|}{ إلى حلد ما } & \multicolumn{2}{|c|}{ موافق } & & \\
\hline & & النسبة & 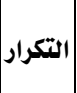 & النسبة & التكرار & النسبة & 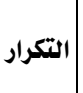 & & \\
\hline,+1 & $\xi \vee,\urcorner \xi$ & 07 & $\wedge \varepsilon$ & 1. & 10 & ץ\& & 01 & |خامة الزى لا تسبب حساسية بالجلد & 1 \\
\hline,$\cdot 1$ & $v \cdot, 7 \wedge$ & ar & 94 & 9 & 9 & rr & $\xi \wedge$ & |خامة الزى لا تولد شحنات كهربائية & $r$ \\
\hline,+1 & $\boldsymbol{1 r}, \boldsymbol{\Sigma \varepsilon}$ & $\mathfrak{\xi}$ & 77 & r. & r. & rq & $\Delta \varepsilon$ & |تصميم الزى يوفر الحماية من مختلف العوامل البيئية. & $r$ \\
\hline,$\cdot 1$ & $1 \xi, 07$ & $\leqslant 7$ & v. & r & rr & rr & $\{\wedge$ & |تصميم الزى لا يسمح بلذخول الأتربة والميكروبات لسطح الجلد. & $\varepsilon$ \\
\hline,$\cdot 1$ & r.., $\cdot$ & 1.. & 10. & - & - & - & - & أحرص على استخدم مكملات الزى (القفازات - غطاء الرأس - الكمامة) & 0 \\
\hline
\end{tabular}

يتضح من الجدول رقم (v) وجود فروق دالة إحصائياً عند مستوى (1) (.) ) بين استجابات

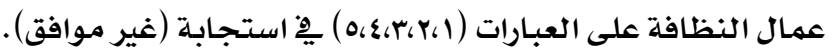

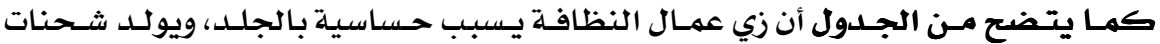

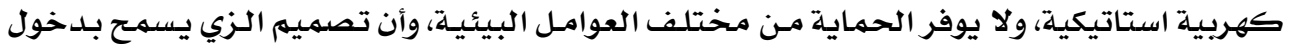

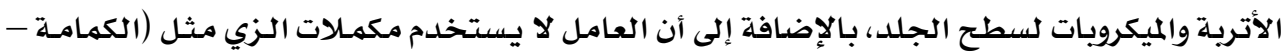

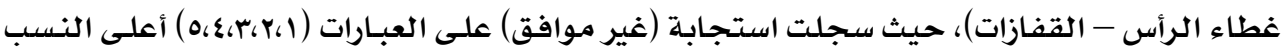

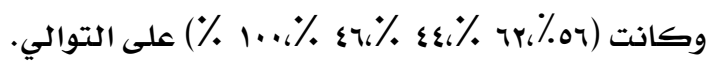

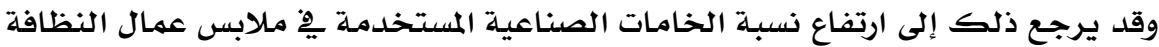

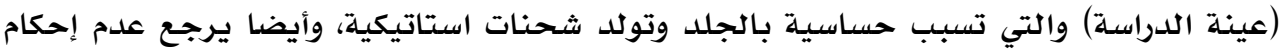

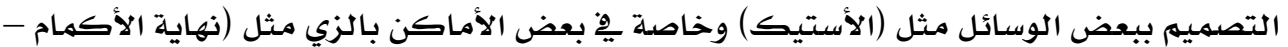

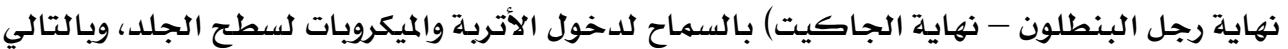

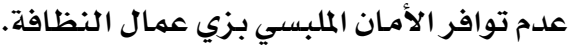

وتتفق هذه النتيجة مـع دراسة (فاطمة على المتولي،ب...r) والتي توصلت إلى ضرورة أن يكون

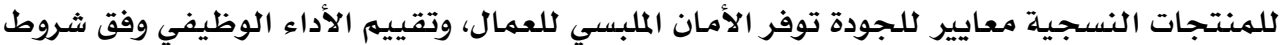

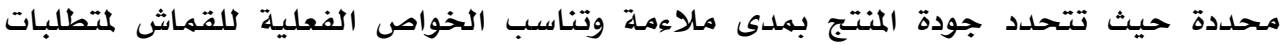

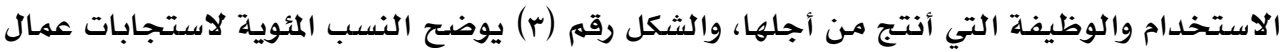

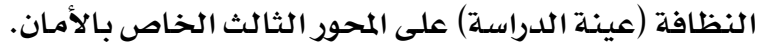




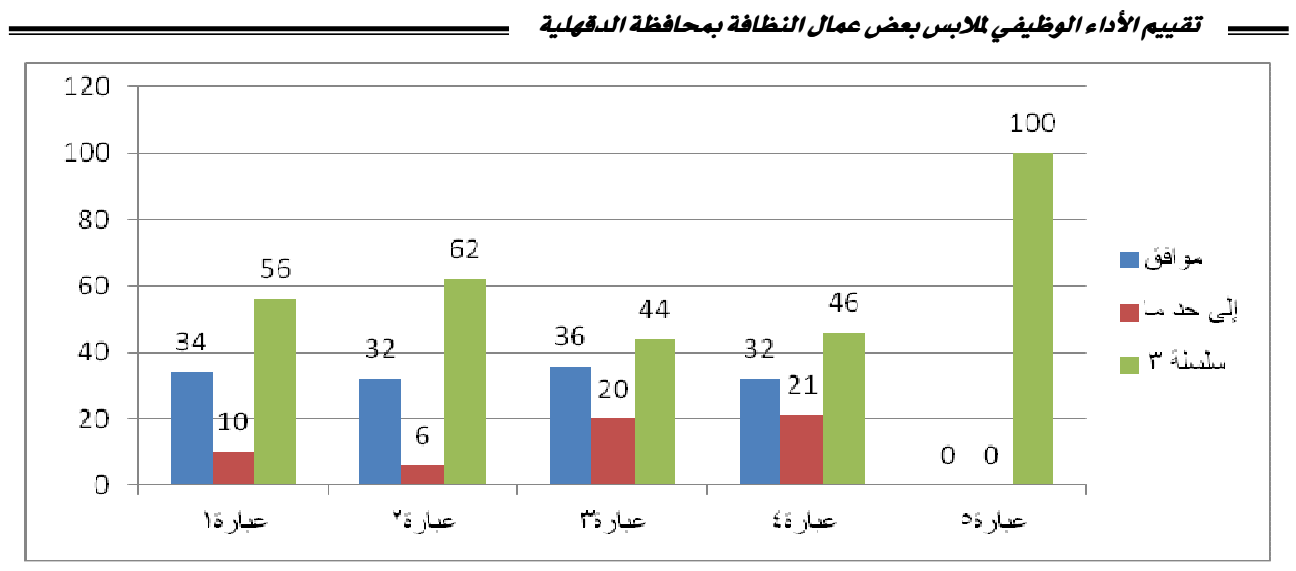

الشكل رقم (r) النسب المئوية لاستجابات عمال النظافة على المحور الثالث (الأمان)

$$
\text { رابعاً: المحور الرابع ( التحمل والعمر الاستهلاكي ) : }
$$

جدول رقم (^) التكرارات والنسب المئوية وقيم كاب ومستوى الدلالة لاستجابات

عمال النظافة على المحور الرابع الخاص بالتحمل والعمر الاستهلاكي ن= .10

\begin{tabular}{|c|c|c|c|c|c|c|c|c|c|}
\hline \multirow{3}{*}{ | مستوى } & \multirow{3}{*}{ SI } & \multicolumn{6}{|c|}{ فئات الاستجابة } & \multirow{3}{*}{ 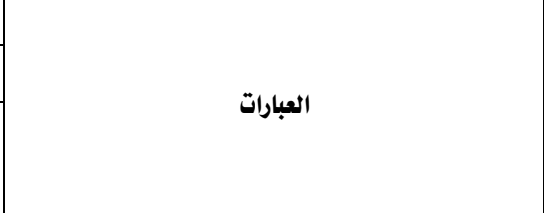 } & \multirow[b]{3}{*}{$\hat{\imath}$} \\
\hline & & \multicolumn{2}{|c|}{ غير موافق } & \multicolumn{2}{|c|}{ 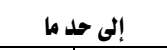 } & \multicolumn{2}{|c|}{ موافق } & & \\
\hline & & ا النسبة & التكرار & النسبة & التكرار & | النسبة.٪ | & التكرار & & \\
\hline,$\cdot 1$ & $\operatorname{irq}, \cdot 1$ & in & rr & $\xi$ & 7 & VA & liv & يتحمل الزي عمليات الفسيل المتكررة. & 1 \\
\hline,$\cdot 1$ & Ar, OY & r. & r. & ir & in & 71 & $1 \cdot r$ & لا تتمزق أقمشة الزي بعد مرور فترة قصيرة من الاستخدام & r \\
\hline,$\cdot 1$ & $\leqslant 7,07$ & $\wedge$ & ir & ६. & 9. & or & va & | لا يحدث تآكل في أماكن معينة مثل (الركبة ـ الكوع ـ الأساور- & $r$ \\
\hline,+1 & $01, r \varepsilon$ & $1 \varepsilon$ & ri & 7. & q. & rq & rq & |يحدث تنسيل لخامة الزي أثثاء الاستعمال. & $\xi$ \\
\hline,$\cdot 1$ & $1 \cdot, 9 r$ & rq & rq & $\leqslant 7$ & 79 & ra & $\xi r$ & |الحياكات المستخدمة في الزي تتفكك بسهولة. & 0 \\
\hline,$\cdot 1$ & rr, rs & r. & \$o & 17 & rz & $\Delta \varepsilon$ & $\wedge 1$ & |يتحمل الزي درجات الحرارة المرتفعة أثناء الفسيل. & 7 \\
\hline,$\cdot 1$ & $\wedge 1, \sum \wedge$ & 71 & $1 \cdot r$ & $1 \varepsilon$ & rl & M & rr & |توجد دعامات (بطانات) في الأساور والياقة. & $\checkmark$ \\
\hline,$\cdot 1$ & ro, OA & rr & r & rq & ra & $\Delta \wedge$ & Av & [يحدث تلف سريع في وسائل غلق الزي سوست ـ أزرار). & $\wedge$ \\
\hline
\end{tabular}

يتضح من جدول رقم (^) وجود فروق دالة إحصائياً عند مستوى (1 (,) بين استجابات عمال

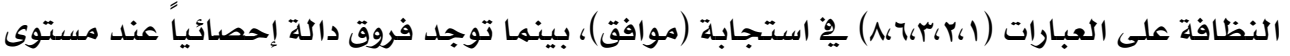

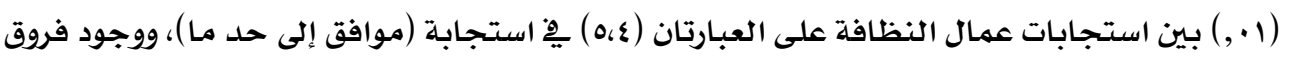

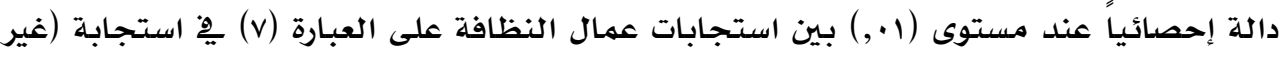


كمـا يتضح مـن الجـدول أن زي عمال النظافـة يمتاز بتحمـل عمليـات الغسيل المتكررة، ولا

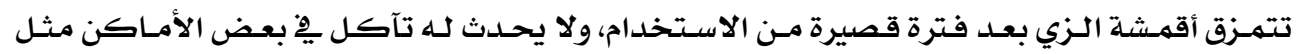

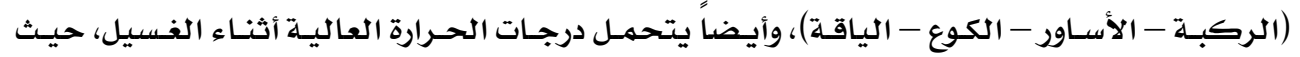

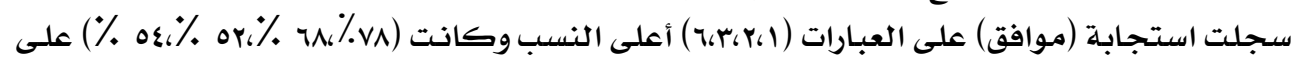
التوالي.

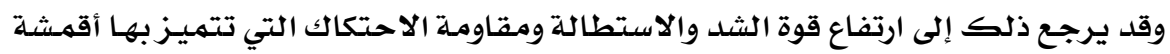

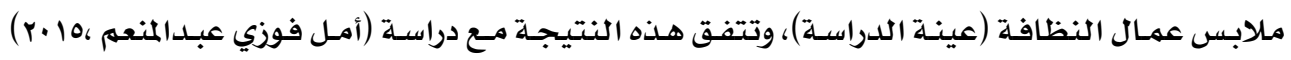

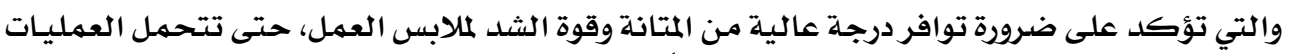

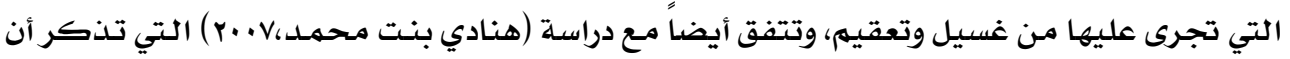

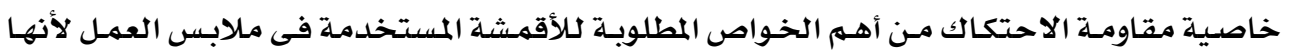

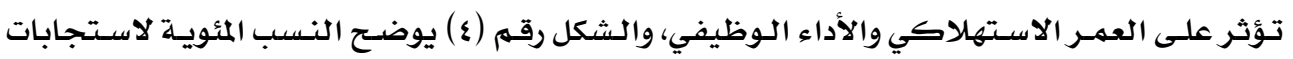

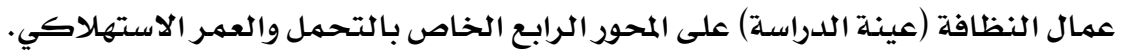

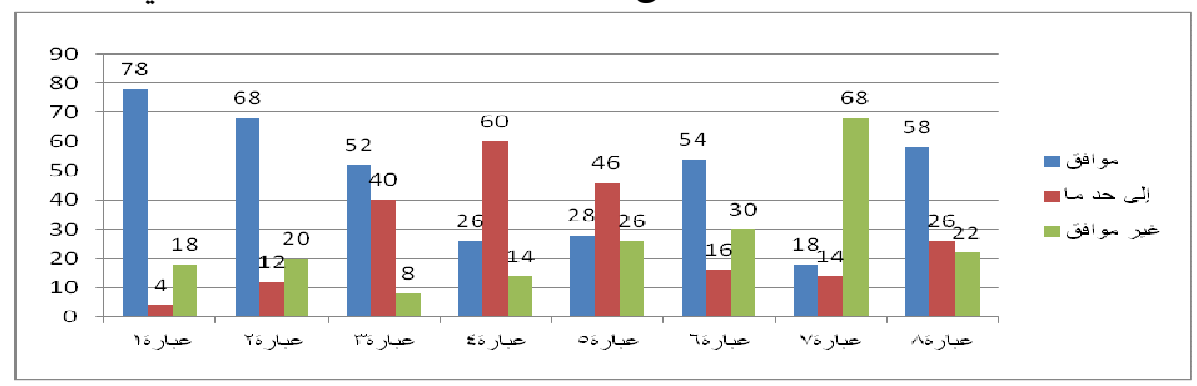

الشكل رقم (ع) النسب المئوية لاستجابات عمال النظافة على المحور الرابع (التحمل والعمر الاستهلاكي) خامساً: الأداء الوظيفي (المحاور الأربعة): جدول رقم (9) التكرارات والنسب المئوية وقيم كاب ومستوى الدلالة لاستجابات

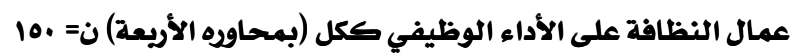

\begin{tabular}{|c|c|c|c|c|c|c|c|c|c|}
\hline \multirow{3}{*}{ مستوى الدلالة } & \multirow{3}{*}{ SIS } & \multicolumn{6}{|c|}{ فئات الاستجابة } & \multirow{3}{*}{ المحاور } & \multirow{3}{*}{ P } \\
\hline & & \multicolumn{2}{|c|}{ غير موافق } & \multicolumn{2}{|c|}{ إلى حد ما } & \multicolumn{2}{|c|}{ موافق } & & \\
\hline & & النسبة\%٪ & التكرار & النسبة\%٪ & التكرار & النسبة\%٪ & التكرار & & \\
\hline, 1 & r\&Y & $\{r, r)$ & 0.1 & 17 & 174 & $r q, r q$ & rAl & الراحة & 1 \\
\hline,$\cdot 1$ & $11, \xi \bullet$ & $\{r, \xi$ & rin & $1 \varepsilon$ & 1.0 & $\varepsilon r, q$ & rrY & العناية & $r$ \\
\hline, .1 & rqu, ro & $\eta, V r$ & rT & $\|,\{V$ & $\wedge 7$ & $\mathrm{rq}, \mathrm{A}$ & $r+1$ & الأمان & $r$ \\
\hline .0 & $\mathrm{v}, \varepsilon \varepsilon$ & ro, ro & $r \cdot q$ & rv,ro & rrY & sv & orr & التحمل والعمر الاستهلاكي & $\varepsilon$ \\
\hline, 1 & $\mid A \cdot, i v$ & $\{r, \xi$ & 1091 & in & 717 & $r q, 7$ & IEAY & الأداء الوظيفي ككل & 0 \\
\hline
\end{tabular}


يتضح من الجدول رقم (ه) وجود فروق دالة إحصائياً عند مستوى (1.,)) بين استجابات

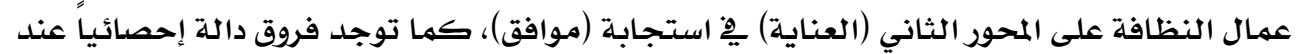

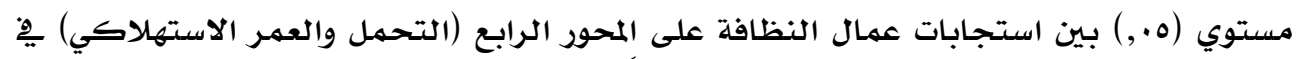

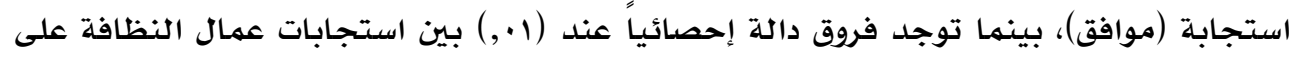

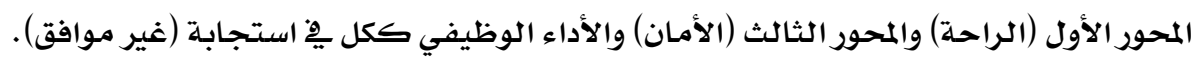
كما يتضح من الجدول أن زي عمال النظافة يمتاز بسهولة الاستخدام (العناية) والتحمل

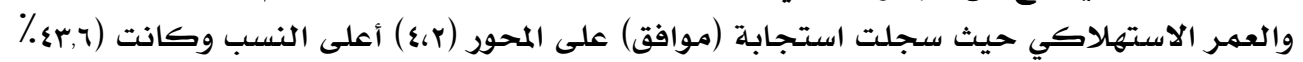

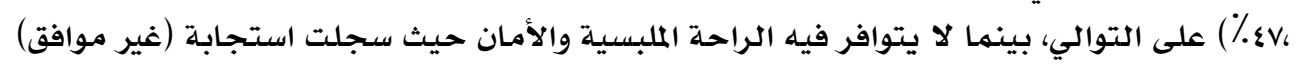

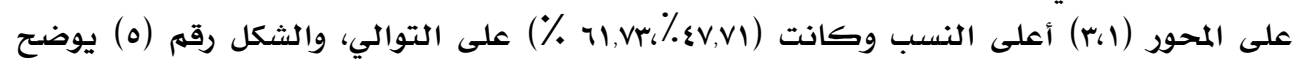
إجمالي النسب المئوية لاستجابات عمال النظافة (عينة الدراسـة) على الأداء الوظيفي ككل (بهحاوره الأربعة).

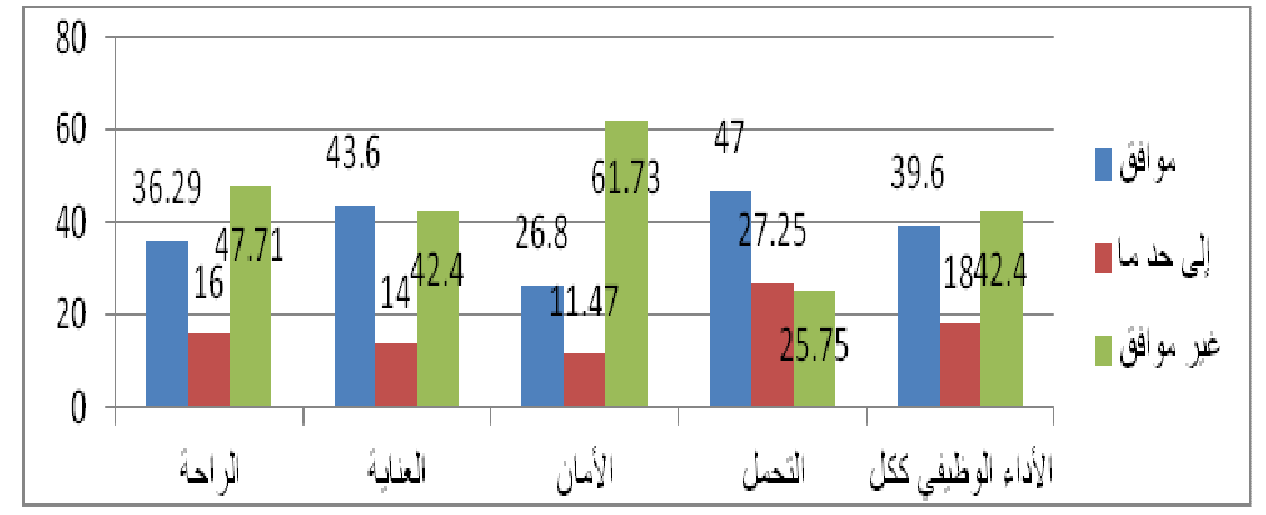

شكل رقم (ه) النسب المئوية لاستجابات عمال النظافة على الأداء الوظيفي ككل (بمحاوره الأريعة) يتضح مما سبق تحقق الفرض الأول من فروض البحث يِّ وجود فروق ذات دلالة إحصائية بين ملابس عمال النظافة بمحافظة الدقهلية من الناحية الوظيفية.

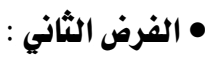

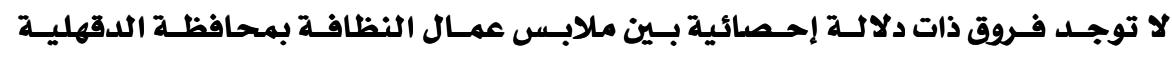
(الرجال- السيدات).

للتحقق من صحة هذا الفرض تم استخدم اختبار(ت) للمجموعات المستقلة، والانحراف

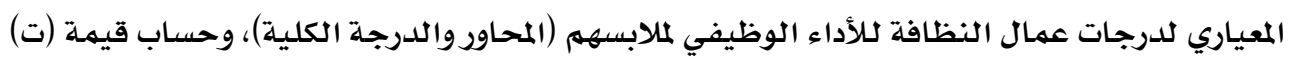

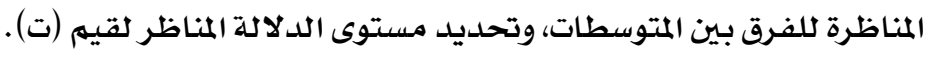




\begin{tabular}{|c|c|c|c|c|c|c|c|}
\hline \multicolumn{8}{|c|}{ جدول رقم ( • ) قيمة (ت) ودلالة الفروق بين متوسطات درجات (عمال النظافة - } \\
\hline |مستوي الدلالة| & قيمة (ت) & درجات الحرية & |الانحراف المياري & المتوسط & |عدد العمال & المجموعة & المحور \\
\hline \multirow{2}{*}{ غير دالة } & \multirow{2}{*}{$1, \cdot \xi$} & \multirow{2}{*}{$1 \xi \Lambda$} & $\{, 0\}$ & Ir,qr & vo & عمال & \multirow{2}{*}{ الأول : الراحة } \\
\hline & & & $r, \wedge 9$ & 17,70 & vo & عاملات & \\
\hline \multirow{2}{*}{,+1} & \multirow{2}{*}{$r, r V$} & \multirow[b]{2}{*}{$1 \varepsilon \Lambda$} & $1, r_{1}$ & 9, or & vo & عمال & \multirow{2}{*}{ الثاني : العناية } \\
\hline & & & $1, \wedge 1$ & $\wedge, 79$ & vo & عاملات & \\
\hline \multirow{2}{*}{ 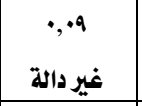 } & \multirow{2}{*}{$1,7 v$} & \multirow{2}{*}{$1 \xi \Lambda$} & $r, 0 q$ & $1 \cdot, r \cdot$ & vo & عمال & \multirow{2}{*}{ الثالث : الأمان } \\
\hline & & & $r, 91$ & $9, r \cdot$ & vo & عاملات & \\
\hline \multirow{2}{*}{,+1} & \multirow[b]{2}{*}{0,14} & \multirow[b]{2}{*}{$1 \varepsilon \Lambda$} & r, ro & $11,1$. & vo & عمال & \multirow[b]{2}{*}{ الرابع : التحمل } \\
\hline & & & $\{, 11$ & 18,97 & vo & عاملات & \\
\hline \multirow{2}{*}{, .0} & \multirow{2}{*}{$r,\{\Lambda$} & \multirow{2}{*}{$1 \leqslant \wedge$} & $9, \wedge$. & $0 ., \mathrm{VI}$ & vo & عمال & \multirow{2}{*}{ المحاور الأربعة } \\
\hline & & & $1 \cdot, 7 r$ & $\{7,7\}$ & vo & عاملات & \\
\hline
\end{tabular}

يتضح من الجدول رقم (1) وجود فروق دالة إحصائياً عند مستوى دلالة ( ا . , ) بين ملابس

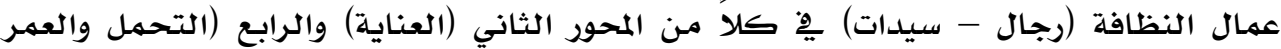

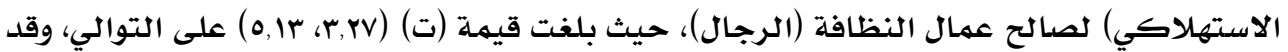

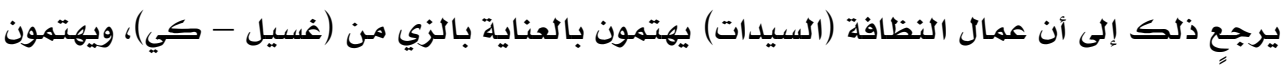

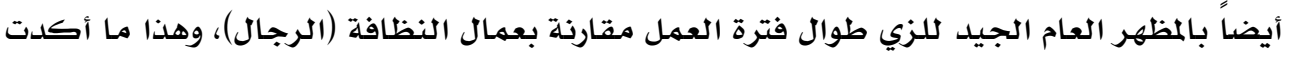

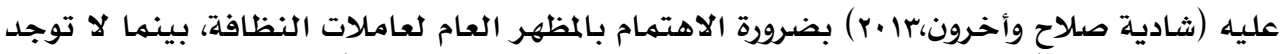

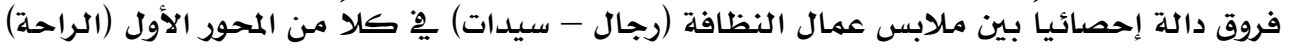

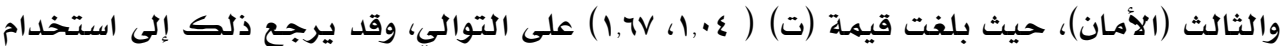

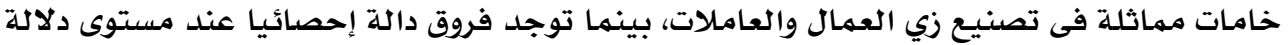

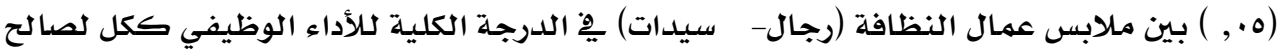

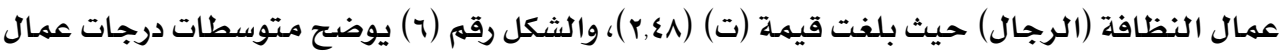

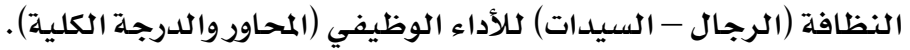

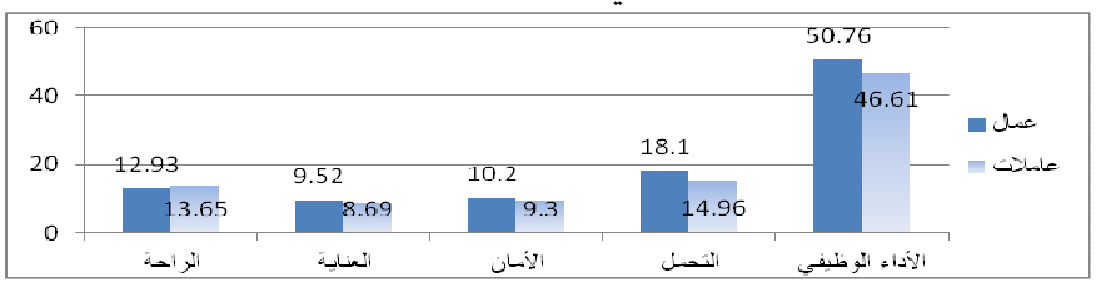

الشكل رقم (ף) متوسطات درجات ملابس عمال النظافة (رجال - سيدات)

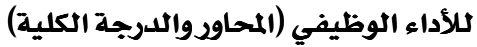


يتضح مما سبق تحقق الفرض الثاني من فروض البحث جزئياً ٌِِ كل من: المحور الأول

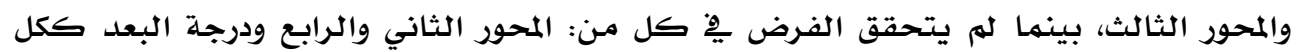

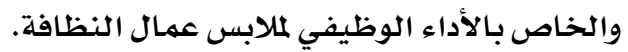
• الفرض الثالث:

توجد علاقة دالة إحصائياً بين خواص الأقمشة المستخدمة لملابس عمال النظافة بمحافظة الدقهلية وجودة الأداء الوظيفي.

للتحقق من صحة هذا الفرض تم استخدام الأسلوب الإحصائي (معامل الجودة) و و

.(Radar Chart)

جدول رقم (11) نتائج قياس الخواص الوظيفية للعينات (محل الدراسة)

\begin{tabular}{|c|c|c|c|c|c|c|c|c|c|c|c|}
\hline 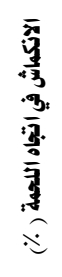 & 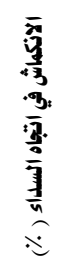 & 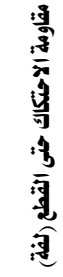 & 量. & 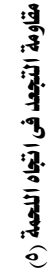 & 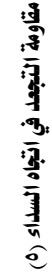 & 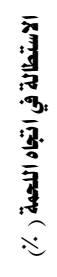 & 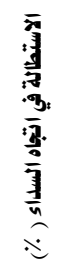 & 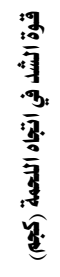 & 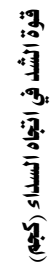 & مواصفة العينة & 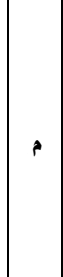 \\
\hline $1, \xi$ & $1, \xi$ & rIII & $r, v$ & Irv & 17. & r & $v, \Delta$ & 77 & $1 . r$ & 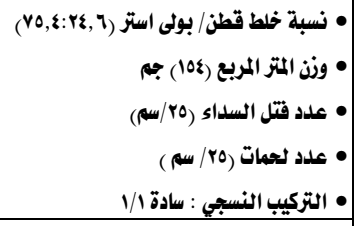 & عينة \\
\hline 1,0 & 1,0 & oro. & $\Lambda, 0$ & lor & Irr & 7,0 & $v$ & $\wedge \wedge$ & ar & 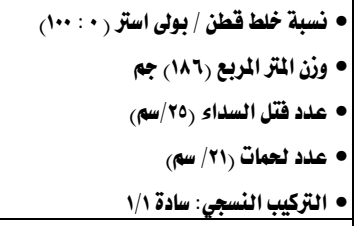 & عينة \\
\hline $1, \xi$ & $1, \xi$ & $707 \mathrm{~V}$ & $r, v$ & $1 \xi$. & 18. & 7,0 & 7,0 & 1.. & 11. & 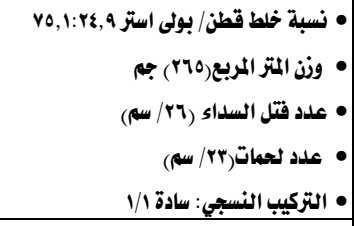 & عينة \\
\hline $1, r$ & $1, r$ & Alrs & $r, r$ & 10r & M. & 1 & $v, 0$ & 1.1 & 10. & 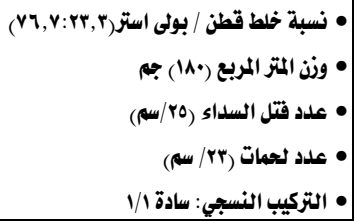 & عينة \\
\hline
\end{tabular}


يوضح الجدول رقم (11) الاختبارات التي أجريت على أقمشة ملابس عمال النظافة (عينة

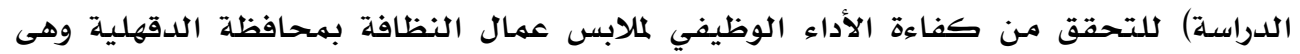

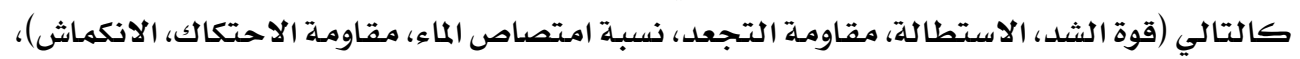

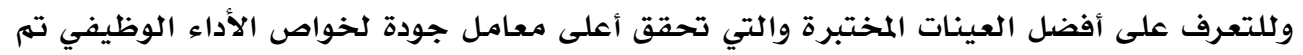

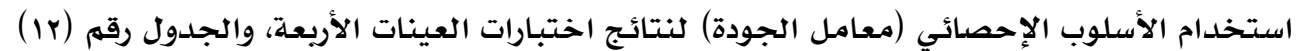

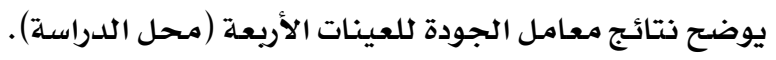
جدول رقم (ir)

نتائج معامل الجودة (\%) للعينات محل الدراسة رجة (1)

\begin{tabular}{|c|c|c|c|c|c|c|c|c|}
\hline 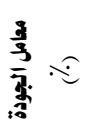 & 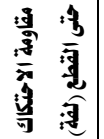 & $\frac{\bar{s}}{\frac{3}{3}}$ & 象 & 曶 & 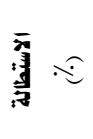 & 瓷 & مواصفة العينة & $p$ \\
\hline 11,10 & $r \Lambda, r$ & $\wedge \Lambda, r$ & $9 r, r$ & 1.. & 1.. & $T V, r$ & 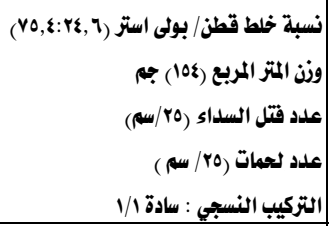 & عينة (ا) \\
\hline VY,O & $7 \xi, 0$ & $r I, \Lambda$ & $\wedge 7,7$ & $A V$ & $9 r, 1$ & rr & | لعبة خلط قطن / بولى استر • : •.1) & عينة (r) \\
\hline $9 \cdot, \xi$ & 1... & $\wedge \Lambda, r$ & $9 r, r$ & $\wedge \xi$ & $\wedge 9,1$ & $A v, r$ & 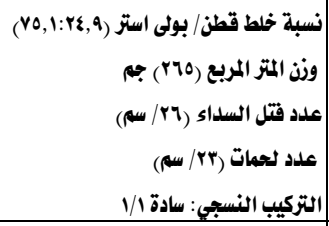 & عينة (") \\
\hline $9 \pi, 1$ & $\wedge \cdot, \vee$ & 1.. & 1.. & 19 & $9 r, 1$ & 1.. & 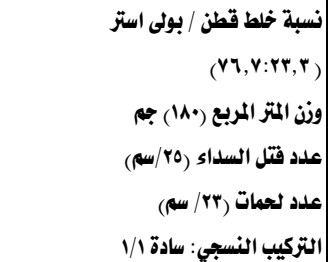 & عينة (\&) \\
\hline
\end{tabular}

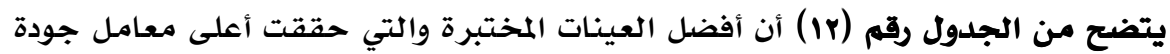

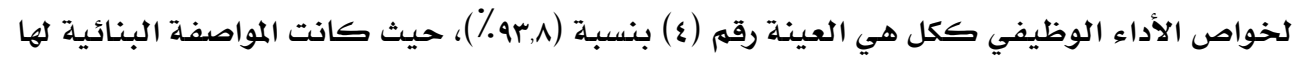

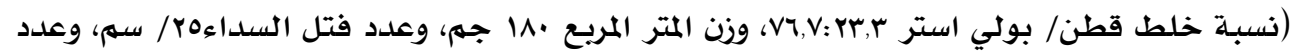


لحمات سب/ سه، وتركيب نسجي سادة //1)، وهذه النتيجة تعد منطقية من حيث أن التركيب

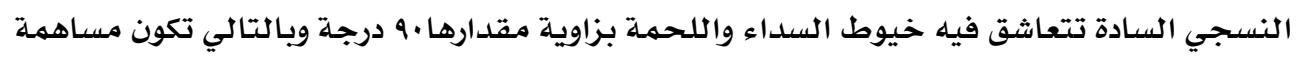

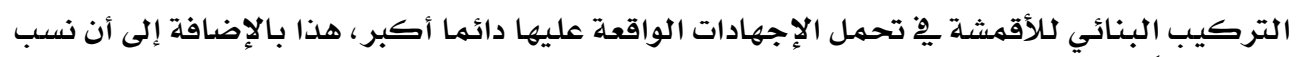

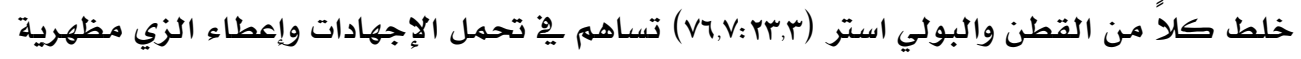

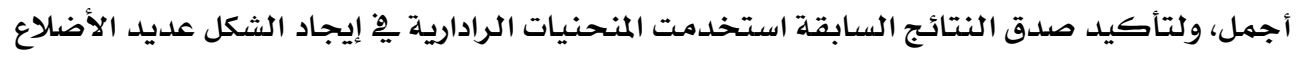

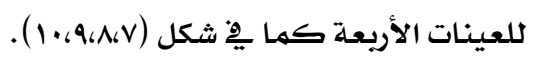

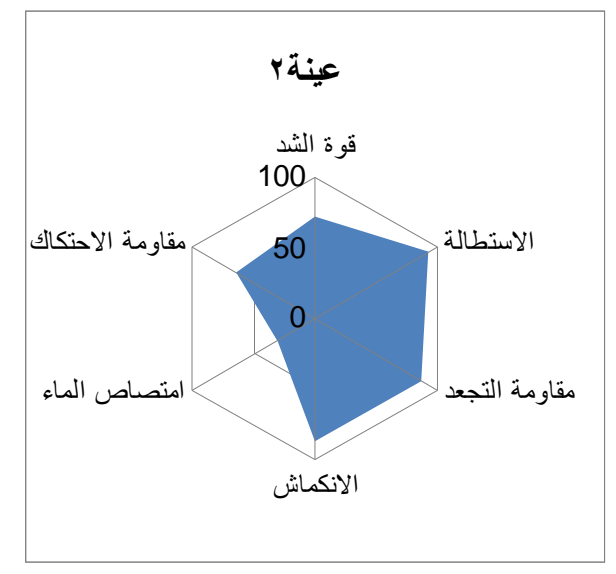

الشكل رقم (^) الخريطة الرادارية

(r) للخواص المقاسة للعينة

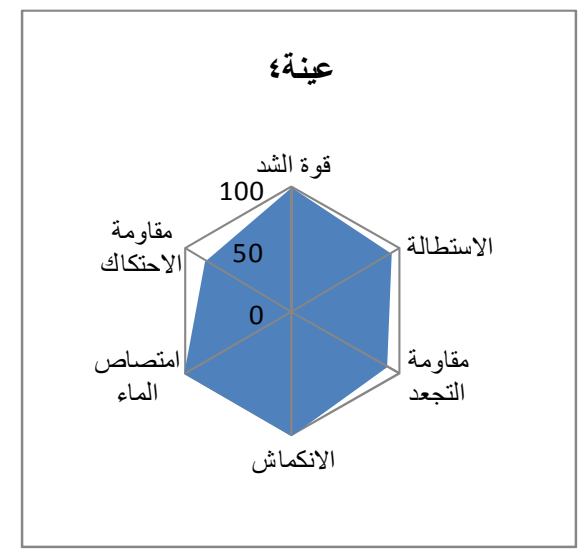

شكل رقم ( ـ ) الخريطة الرادارية

للخواص المقاسة للعينة (ع)

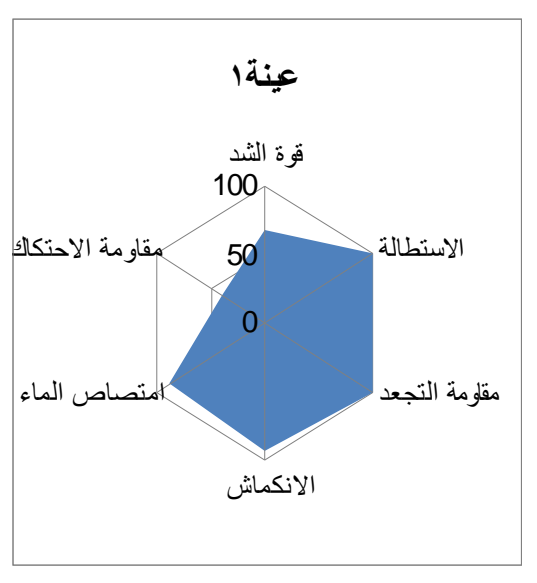

الشكل رقم (v) الخريطة الرادارية

للخواص المقاسة للعينة (1)

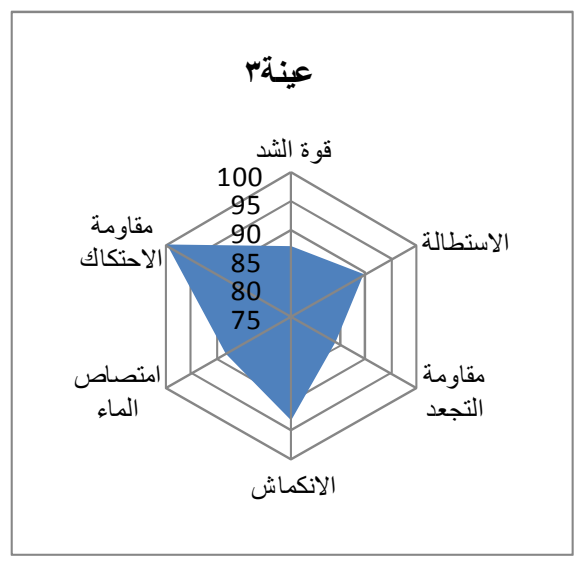

شكل رقم (4) الخريطة الرادارية

للخواص المقاسة للعينة (r) 


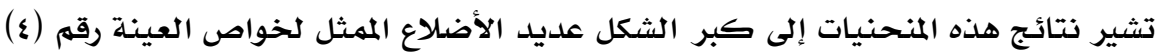

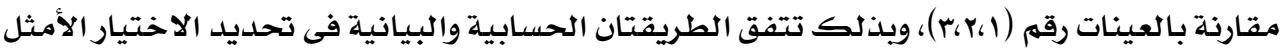
لكلأقمشة المختبرة.

يتضح مما سبق تحقق الفرض الثالث من فروض البحث فى وجود علاقة بين خواص الأقمشة المستخدمـة لملابس عمال النظافة بمحافظة الدقفهلية وجودة الأداء الوظيفي. ا.زى عمال النظافة بمحافظة الدقهلية يتوافر فيه عاملي (العناية وسهولة الاستخدام -

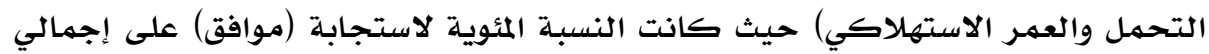

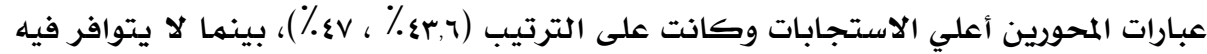

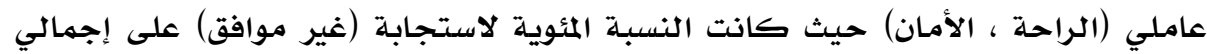

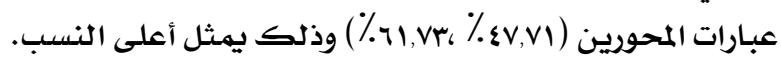
r.وجود فروق بين ملابس عمال النظافة بمحافظة الدقهلية من الناحية الوظيفية (الرجال -

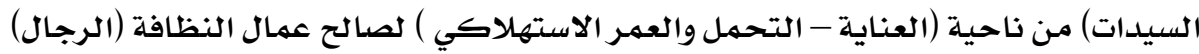

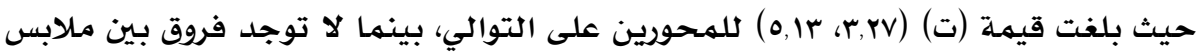

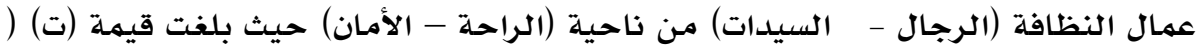

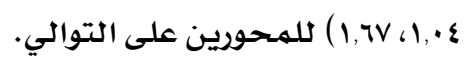

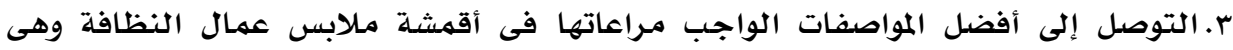
كالتالي:

$$
\begin{aligned}
& \text { • نسبة الخلط (قطن / بولى استر r. (VI,Yr.r). } \\
& \text { • (وزن المتر المريع (•ها جهم). }
\end{aligned}
$$

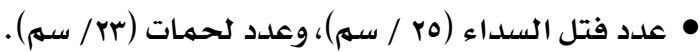

$$
\begin{aligned}
& \text { • التركيب النسجي سادة (1/1). }
\end{aligned}
$$

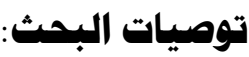

ا ـ عدم استخدام خامة البولي استر كخامة خالصة ِِّ تصنيع ملابس العمال وخاصدة ملابس عمال النظافة. r . ضرورة عمل مقاسات مختلفة لزى عمال النظافة ليتناسب مـع جميع العمال.

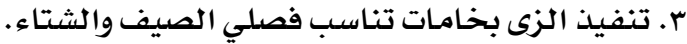

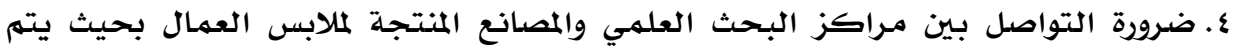

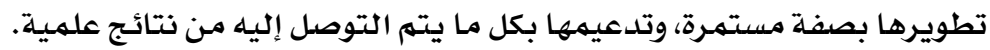

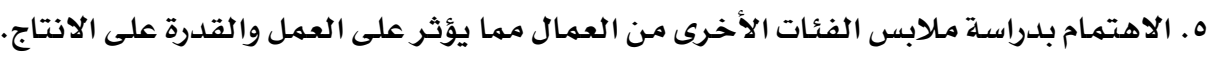
ا. أسماء حميدة محمد (q. (ب)): دراسة تأثير المواد الكيميائية على العمر الاستهلاكي لملابس الحماية للعاملين بِ مجال الصناعة، رسالة ماجستير، كلية الاقتصاد المنزلي، جامعة المنوفية. 
r. أمل فوزى عبدالمنعم (10) (10): تقييم الملابس الطبية المستخدمة بالمستشفيات وتحديد أنسب المعايير لاختيارها، رسالة دكتوراه، كلية التربية النوعية، جامعة المنصورة.

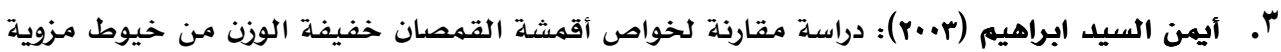

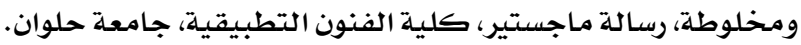

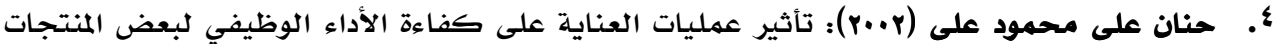
النسجية القطنية، رسالة ماجستير، كلية الفنون التطبيقية، جامعة حلوان.

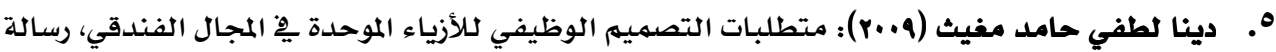

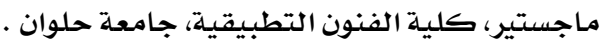

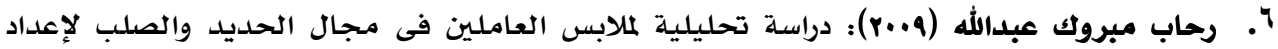

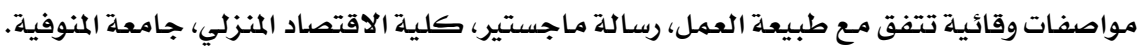

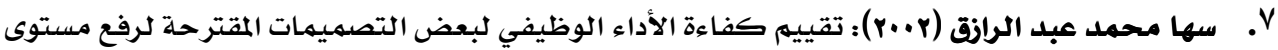

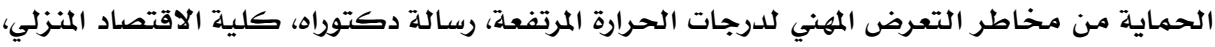
جامعة المنوفية. ^. شادية صلاح ورانيا مصطفي (rا.r): تصميم وإنتاج زىى عاملات النظافة فى ضوء المتطلبات الوظيفية

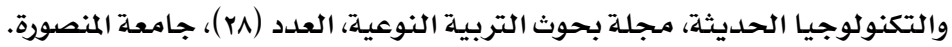

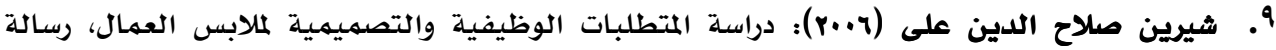
ماجستير، كلية الفنون التطبيقية، جامعة حلوان.

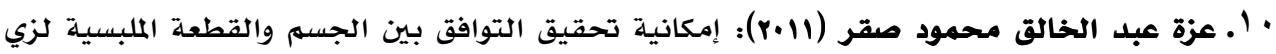

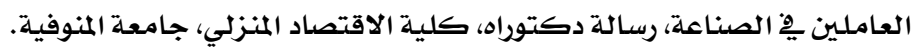

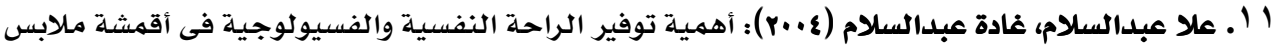

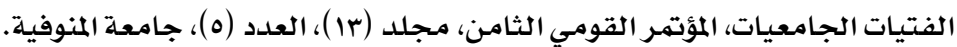

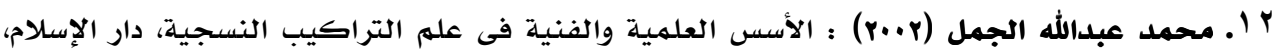
المنصورة.

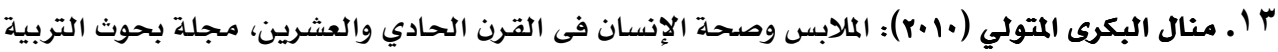

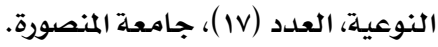

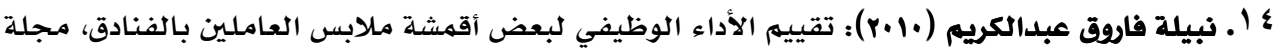
بحوث التربية النوعية، العدد الثامن عشر، جامعة المنصورة.

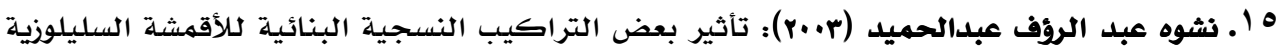

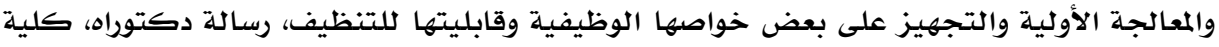
الاقتصاد المنزلي، جامعة المنوفية.

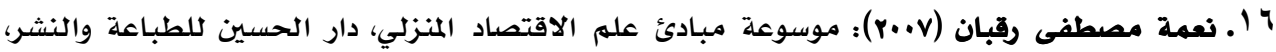




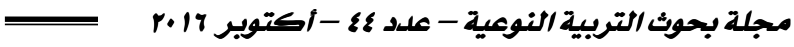

V I هشام أحمد عصام (.1.r): التصميم والتشغيل للملابس الطبية فى ضوء مفاهيم الأمان والسلامة

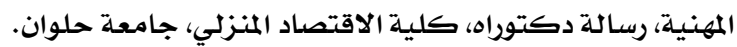

18. Patrick john-(1995): Fashion design illustration children" - Ireland.

19. Pratt, M.J,(1993): On the Meaning and impact of organizational dress.

20. Academy Of Management Review.18.

21. Kathryn L, Hatch (1992): Textile Science, West Publishing company, U.S.A

22. http//:www.vitliligoarab.net 


\section{هلمق (1) هوان (1)}

استمارة استبيان تستهلدف الوقوف على الجوانب الإيجابية والسلبية لملابس عمال النظافة

\section{السادة العاهلين بهيئة النظافة:}

بعد التحية ،"، ب،

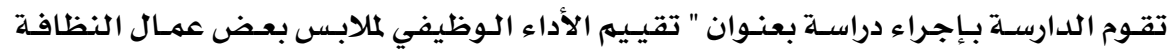
بمحافظة الدقهلية"، وذلك للوقوف على الجوانب الإيجابية والسلبية بملابس عمال النظافة.

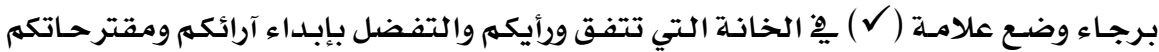

$$
\text { التي تفيد ِِّ هذا الشأن. }
$$

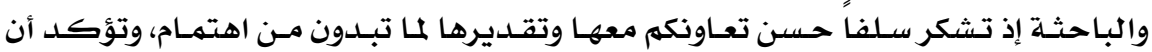

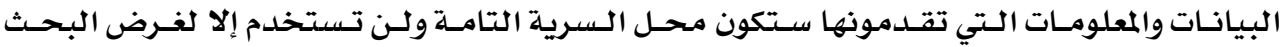

،u“، مع خالص الشكروالتقدير

بيانات:

$$
\text { الاسم (اختياري): }
$$

וالسن:

الحالة التعليمية:

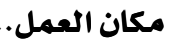

$$
\text { - }
$$

- أرتدي زي مكون من:

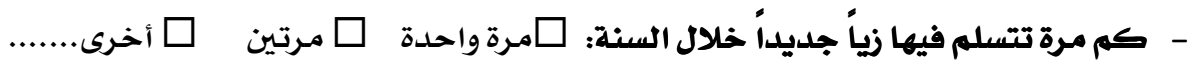




\begin{tabular}{|c|c|c|c|c|}
\hline 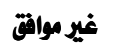 & موافق إلى حدما & 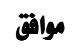 & 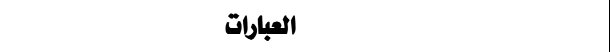 & s \\
\hline \multicolumn{5}{|c|}{ الحهور الأول : الراحة } \\
\hline & & & | يتناسب الزي مع فصلي الصيف والشتاء. & 1 \\
\hline & & & ا المقاسات المتوفرة من الزي تلبي احتياجاتي. & r \\
\hline & & & أشعر بالراحة عندما أرتدي الزي أثناء العمل. & $r$ \\
\hline & & & توجد صعوبة عند ارتداء وخلع الزي. & $\varepsilon$ \\
\hline & & & خامة الزي مريعة وتتتص العرق. & 。 \\
\hline & & & ل يعمل الزي خلال فترة العمل على رفع درجة حرارة جسمي. & 1 \\
\hline & & & 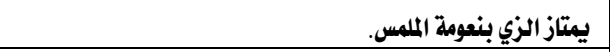 & $r$ \\
\hline \multicolumn{5}{|c|}{ الحمور الثاني: سهولة الاستخدام (العناية) } \\
\hline & & & | يتعرض الزي للاتساخ بسرعة. & 1 \\
\hline & & & تزال البقع من الزي بسهولة أثناء الفسيل. & $r$ \\
\hline & & & ي يكمش الزي (تفير في الطول والعرض) بعد الغسيل. & $r$ \\
\hline & & & إيحتاج الزي للفسيل أكثر من مرة خلال الأسبوع. & $\varepsilon$ \\
\hline & & & | يحتاج الزي للكي بعد عملية الفسيل. & $\circ$ \\
\hline \multicolumn{5}{|c|}{ المهور الثالث: الأههان } \\
\hline & & & خامة الزي لا تسبب حساسية بالجلد. & 1 \\
\hline & & & الزى لا يولد شحنات كهربائية. & r \\
\hline & & & تصميم الزي يوفر الحماية من مختلف العوامل البيئية. & $r$ \\
\hline & & & تصميه الزي لا يسمح بدخول الأتربة والميكروبات لسطح الجلد. & $\xi$ \\
\hline & & & أحرص على استخدم مكملات الزي (القفاز_ غطاء الرأسـ الكمامة). & ० \\
\hline \multicolumn{5}{|c|}{ الحهور الرابع: التحمل والعمر الاستهلاكي } \\
\hline & & & | يتحمل الزي عمليات الفسيل المتكررة. & 1 \\
\hline & & & لا تتمزق أقفشة الزي بعد مرور فترة قصيرة من الاستخدام. & r \\
\hline & & & لا يحدث تآكل في أماكن معينة مثل (الركبة ـ الكوع ـ الأساور ـ الياقة). & $r$ \\
\hline & & & يحدث تنسيل لخامة الزي أثناء الاستعمال. & $\varepsilon$ \\
\hline & & & | الحياكات المستخدمة في الزي تتفكك بسهولة. & 。 \\
\hline & & & يتحمل الزي درجات الحرارة المرتفعة أثثاء الفسيل. & 1 \\
\hline & & & توجد دعامات (بطانات) في الأساور واللياقة. & $r$ \\
\hline & & & يحدث تلف سريع في وسائل غلق الزي ( سوست ـ أزرار). & $\wedge$ \\
\hline
\end{tabular}


ملحق (Y) أسماء السادة المحكمين لاستمارة الاستبيان

\begin{tabular}{|c|c|c|}
\hline الوظيفة & الاسم - تاسم & $p$ \\
\hline أستاذ الملابس والنسيج ـ كلية الاقتصاد المنزلي - جامعة حلوان & أ.د / ماجده محمد ماضي & 1 \\
\hline أستاذ ورئيس قسم الملابس والنسيج - كلية الاقتصاد المنزلي - جامعة المنوفية & أ.د/ نشأت نصر الرفاعى & r \\
\hline أستاذ الملابس والنسيج - كلية الاقتصاد المنزلي - جامعة المنوفية & أ.م. د / إيهاب أحمد محمد & r \\
\hline مدرس الملابس والنسيج ـ كلية الاقتصاد المنزلي - جامعة المنوفية. & أ.م. د/ معدوح أحمد مبروك & $\xi$ \\
\hline أستاذ الملابس والنسيج المساعد - كلية الاقتصاد المنزلي - جامعة حلوان & أ.م. د/ وسام حمد إبراهيم & ○ \\
\hline مدرس الملابس والنسيج ـ كلية الاقتصاد المنزلي - جامعة حلوان & ل خالد مصطفى عابل & 9 \\
\hline ملدرس الملابس والنسيج - كلية الاقتصاد المنزلي - جامعة المنوفية & د/ أحمد رمزي عطا اللّ & $\checkmark$ \\
\hline ملدرس المناهج وطرق التدريس ـ كلية التربية النوعية ـ جامعة المنصورة & م/ مسوزان عبد الملالك & $\wedge$ \\
\hline ملدرس المناهج وطرق التدريس ـ كلية التربية النوعية - جامعة المنصورة & د/ إيهان فوزي عبدالمنعم & 9 \\
\hline ملدرس الملابس والنسيج - كلية الاقتصاد المنزلي - جامعة المنوفية & م/ د اهام محمد قتحي & $1 \cdot$ \\
\hline
\end{tabular}




\section{Assess The Functionality of Some Clothes Hygiene Dakahlia Governorate Workers}

\section{Abstract}

Targeted research to identify the level of worm functionality of clothes cleaners dakahlia governorate (men - women).

in order to stand on the positive and negative aspects and identify all necessary measures to this quality functional requirements of clothing, achieving quality in use

Application was on a sample of (150) of the hygiene workers dakahlia of them workers (75 men - 75 women) the search tool is a questionnaire directed to the cleaners included on four axes (comfort - care - safety - endurance and old consumer) has been judged by a group of specialists, in addition to a set of tests on samples of fabrics used in order to verify the research hypotheses

The results led to the existence of significant differences between the clothes cleaners dakahlia governorate functionally, and also the presence of statistically significant differences between the clothes of both men and women. the results also proved that uniform cleaners dakahlia governorate where workers are available (and ease of use, durability and age consumer care) where the percentage of response (ok) to the total axes phrases highest responses were respectively (43.6\% -47\%), while not having the workers (comfort and safety), where a higher percentage of response (not ok) on total axes phrases $(47.71 \%-61.73 \%)$ and it represents the highest percentages.

Through the study of properties of functional for some of the samples used in the clothes cleaners dakahlia governorate sample achieved a no. 4 specification constructions (mixing cotton polyester ratio 23.3: 76.7 of weight per square meter of $180 \mathrm{~g}$ and the number of wicking box warp $25 \mathrm{~cm}$ and number of nevi $23 \mathrm{~cm}$ and the installation of textile 1/1) highest quality plants( $93.8 \%) \%$ 